\title{
MPC Framework for the Energy Management of Hybrid Ships with an Energy Storage System
}

\author{
Spyros Antonopoulos ${ }^{1,2, *(1)}$, Klaas Visser ${ }^{1}$, Miltiadis Kalikatzarakis ${ }^{2}$ and Vasso Reppa ${ }^{1}$ (D) \\ 1 Faculty of Mechanical, Maritime and Materials Engineering, Delft University of Technology, \\ 2628 CD Delft, The Netherlands; K.Visser@tudelft.nl (K.V.); V.Reppa@tudelft.nl (V.R.) \\ 2 DAMEN Naval BV, Department of Research and Technical Support, 4381 NK Vlissingen, The Netherlands; \\ M.Kalikatzarakis@damennaval.com \\ * Correspondence: spantonopoulos@gmail.com
}

check for updates

Citation: Antonopoulos, S.; Visser, K.; Kalikatzarakis, M.; Reppa, V. MPC Framework for the Energy Management of Hybrid Ships with an Energy Storage System. J. Mar. Sci. Eng. 2021, 9, 993. https://doi.org/ $10.3390 /$ jmse9090993

Academic Editors: Kari Tammi, Dimitrios V. Lyridis and Charis Ntakolia

Received: 21 July 2021

Accepted: 4 September 2021

Published: 11 September 2021

Publisher's Note: MDPI stays neutral with regard to jurisdictional claims in published maps and institutional affiliations.

Copyright: (c) 2021 by the authors. Licensee MDPI, Basel, Switzerland. This article is an open access article distributed under the terms and conditions of the Creative Commons Attribution (CC BY) license (https:// creativecommons.org/licenses/by/ $4.0 /)$.

\begin{abstract}
This paper proposes an advanced shipboard energy management strategy (EMS) based on model predictive control (MPC). This EMS aims to reduce mission-scale fuel consumption of ship hybrid power plants, taking into account constraints introduced by the shipboard battery system. Such constraints are present due to the boundaries on the battery capacity and state of charge (SoC) values, aiming to ensure safe seagoing operation and long-lasting battery life. The proposed EMS can be used earlier in the propulsion design process and requires no tuning of parameters for a specific operating profile. The novelties of the study reside in (i) studying the impact of mission-scale effects and integral constraints on optimal fuel consumption and controller robustness, (ii) benchmarking the performance of the proposed MPC framework. A case study carried out on a naval vessel demonstrates near-optimal and robust behaviour of the controller for several loading sequences. The application of the proposed MPC framework can lead to up to 3.5\% consumption reduction due to utilisation of long term information, considering specific loading sequences and charge depleting (CD) battery operation.
\end{abstract}

Keywords: energy management strategies; model predictive control; hybrid propulsion; energy storage system; ship control

\section{Introduction}

\subsection{Regulatory and Technical Context for Battery Installations}

Reduction of the environmental impact of ships has been a subject of concern and has been addressed by regional and global regulators. According to the fourth International Maritime Organisation (IMO) greenhouse gas (GHG) study in 2020 [1], shipping contributes an average of $2 \%$ of total anthropogenic $\mathrm{CO}_{2}$ emissions, while with business as usual (BAU) projections, the $\mathrm{CO}_{2}$ emissions are expected to increase by $0-50 \%$ compared to the 2018 figure. To that end, IMO has been actively involved in, amongst other activities, enhancing the energy efficiency of ships, within the MARPOL Annex VI regulatory framework. The IMO's efforts aim to reduce GHG emissions to 50\% of the 2008 baseline value by 2050. According to all future projections in the study, it is difficult to achieve the $\mathrm{CO}_{2}$ reduction goal solely by means of more efficient conventional propulsion and lower sailing speeds. Towards that end, several alternatives to conventional shipboard energy generation have been proposed in the literature. Listing only some of the proposed alternatives, reduction of emissions compared to conventional power plants has been reported by using liquefied natural gas (LNG) fuel [2,3], ammonia fuel and ammonia injection [4,5], biofuels [6,7], and energy storage systems (ESSs-list of abbreviations given in Table A2).

Although ultracapacitors are utilised when surges of power are needed by electrical consumers on-board (e.g., weapon systems on naval vessels) [8], the scope of this study is limited to batteries, as the most researched and most promising ESS in the maritime sector $[9,10]$. The price of lithium-ion batteries has plummeted over the past 10 years, by 
approximately $\$ 1000 / \mathrm{kWh}$, down to the 137 mark in 2020 [11]. Price projection to 2030 predicts prices as low as $\$ 50 / \mathrm{kWh}$ for batteries with silicon alley cathodes, which are cheaper to produce and more energy dense $(205 \mathrm{Wh} / \mathrm{kg}$ over $155 \mathrm{Wh} / \mathrm{kg}$ compared to graphite cathodes) [12]. Those rapidly changing price and density values have madeshipboard battery pack installations an attractive solution for fuel consumption reduction in the years to come.

Tugboats, ferries, offshore support vessels, and naval vessels operate for a significant portion of their mission at low power demand. In such cases, the conversion losses associated with hybrid or electric power transmission (or propulsion) are compensated by avoiding inefficient part load operation of the prime mover(s). Geertsma et al. [9] review the fuel savings induced by hybrid or electric propulsion in the corresponding literature. In short, gas turbines in frigates, sized-for-availability internal combustion engines in towing or patrol vessels, and transit prime movers in dynamic positioning operation of offshore support vessels can all benefit from hybrid propulsion, with fuel savings of even more than $10 \%$. On the other hand, purely electric propulsion installations (no mechanical power transmission) are mostly driven by particular necessities such as heavy hotel loads, operational robustness, space limitations, and low noise emissions.

The same study reviews the benefits of further introducing shipboard ESSs in hybrid propulsion powertrains. Power supply from an ESS can reduce the amount or size of the internal combustion (IC) engines by extending the operating envelope or by providing availability and overcoming the necessity of an emergency generator. Operational and maintenance costs can be reduced by offsetting the operating point to the most efficient operating region via (dis)charging, or by even switching off engines in part load operation.

In [10] the limitations of shipboard ESSs, particularly batteries, have been examined for charge sustaining (CS) battery operating mode (which means no charging from ashore). With a reduced model description, the study concludes that electric propulsion with a gas engine is a viable alternative to utilising a lithium-ion battery installation for fuel efficiency gains. Hybrid propulsion has significantly smaller operating regions where batteries yield efficiency gains, from below $50 \%$ of the propulsive load found in electric propulsion, to below $10 \%$. IC engines with a flatter efficiency curve, such as engines with sequential turbocharging, show no efficiency gains due to use of batteries across their operating range. From this and similar studies [13-15] it is found that:

1. The shape of the efficiency curve of the prime mover is the dominant decisive factor for the applicability of an ESS installation

2. When an ESS replaces engine power instead of adding power to an existing engine rating, the efficiency gains are smaller especially at nominal loads

3. In electric propulsion, most conversion losses introduced by an ESS are already in place

4. A DC grid allows for use of non-fixed-speed generator sets and consequently affects the powertrain efficiency in favour of using generator sets and not ESSs

5. Efficiency gains in electric propulsion due to ESSs are found to be $4.7-7.8 \%$ at $50 \%$ load and $18-30 \%$ at $15 \%$ load.

Hybrid propulsion is also found to yield efficiency benefits when combined with a battery unit in charge depleting (CD) mode (shore charging) [16]. It has had commercial success in tugboats by Damen and yachts by Feadship [9]. In [17], four different propulsion configurations in megayachts have been compared and significant advantages in hybrid propulsion have been identified when combined with fast shore charging in marinas with local smart grids. The feasibility of zero-emission high-speed catamaran vessels has been one of the subjects for $[18,19]$, where the importance of charging stations has also been identified as crucial. Finally, battery installations can be combined with fuel cell systems on board ships in order to improve efficiency and dynamic behavior [20,21].

The environmental analysis of battery installations should not be limited to efficiency benefits. An approach taking into account different impact categories, accurate measurements and the life-cycle (life cycle assessment) of the vessel is capable of providing full 
insight into the environmental benefits of shipboard battery systems. For example, in [22] a holistic investigation of a fully electric vessel highlights the critical contribution of energy generation and transportation in the overall environmental impact of electrified ships.

\subsection{Energy Management Stragegies and Problem Definition}

An effective energy management strategy (EMS) is crucial for the application of shipboard ESSs. An EMS functions as a high-level control unit determining the control inputs to the powertrain. Those inputs correspond to the additional degrees of freedom introduced by the ESS and can be selected appropriately to minimise an objective function, most commonly fuel consumption. The aforementioned efficiency gains cannot be realised without the use of an advanced EMS [16]. A comprehensive overview of advanced EMS which can be implemented in real-time is given in [23] and categorised into predictive controllers and controllers derived from the optimal control theory (ECMS). These strategies are separated from rule-based (RB) time-invariant feedback controllers (heuristic rules or static feedback maps).

Conventional shipboard EMSs use rule-based (RB) controllers. These are tuned specifically for each application, for a given operating profile and power plant, while they are also inherently suboptimal and unable to adhere to the state constraints on the battery state of charge $(\mathrm{SoC})$, especially when the operating profile changes [16]. SoC constraints aim to ensure safe sea-going operation (by ensuring battery availability) and long-lasting battery life. A fuzzy logic RB controller used in [21] proved to be effective in maintaining SoC constraints within the battery operating boundaries for a complex powertrain which combined fuel-cells with a battery and ultra-capacitor installation. However, this controller, as well as another fuzzy logic implementation in [24] is based on heuristic rules and its performance in terms of consumption can be improved [23].

Recent research on advanced shipboard EMS showed that strategies based on standard and adaptive equivalent consumption minimisation strategies (ECMSs) are also suboptimal when the operating profile changes significantly [16]. In [25], the implemented ECMS is unable to prove reliable in peak load demand when the batteries are depleted. With ECMS, only instantaneous operating constraints are considered (e.g., maximum main engine power) and integral constraints imposed by the battery and charge-sustenance are only implicitly incorporated through the equivalence factor, which is tuned offline for specific operating profiles. This leads to either suboptimal or invalid, i.e., incapable of meeting the power demand or the SoC constraints, control strategies, as opposed to predictive controllers as in [26], where such constraints are integrated.

In a recent study [27], a multi-layered optimisation scheme uses ant colony optimisation (ACO) to address the deviation between the terminal $\mathrm{SoC}$ value and its target by optimising the equivalence factor of an ECMS control unit. However, the study did not compare the fuel consumption reduction results to an exhaustive optimal solution; hence the suboptimal behaviour of ECMS during significant load changes reported in [16], which is inherent to instantaneous optimisation, should be assumed. In [20], a multi-scheme EMS which alternates between an ECMS strategy and three heuristic and conventional control strategies takes into account the $S o C$ constraints, although the results were also not compared to an optimal solution.

In a study addressing complex non-linear models [28], an instantaneous optimisation model-based EMS utilises a particle swarm optimisation (PSO) solver to minimise fuel consumption in the shipboard power plant. However, this approach does not consider future disturbances, operating profiles or any other future component in the formulations, yielding a suboptimal charge depleting-charge sustaining (CD-CS) discharging strategy for the battery. Finally, both rule-based and ECMS strategies are tuned either onboard or by using high-fidelity models and specific operating profiles $[16,25,26]$. This makes the deployment of the existing strategies difficult during the concept and early engineering design phase. During the early design stage, the decisions about the propulsive layout and the sizing of the components are made. Due to the EMS also affecting the viability of an 
ESS installation [10] it is potentially beneficial for an EMS to be deployed in low fidelity systems during early design.

In model predictive control (MPC) the future disturbance estimation over a set prediction horizon span is made online, then a quadratic programming $(\mathrm{QP})$,dynamic programming (DP), or other optimisation solution is used to find the optimal control sequence for a control horizon span, which may not necessarily be of the same length $[23,29,30]$. MPC is computationally expensive and requires an accurate model description of the system to yield satisfactory results, while, in order to be effective, prediction techniques must be used [31]. In [32], an MPC EMS is proposed, utilising intelligent transportation systems (ITS) for driving cycle prediction. A combination of route prediction from the telematics system together with MPC for powertrain control has also been implemented in [33]. Online implementations of predictive control with information supplied by the GPS and the traffic-flow information systems yield near-optimal results in [34].

Shipboard MPC implementations may function as either power or energy management strategies depending on their timescale and objective function. If the timescale of the control horizon is in the order of several seconds and total fuel consumed is not in the objective function, the strategies can be classified as power management strategies. Such controllers take into account the transient behaviour of the powertrain and ship system. For instance, in [35], the power demand fluctuations (in the order of few seconds) in various sea states due to the propeller load are mitigated, and in [36], the nonlinear ship response of an offshore support vessel due to environmental disturbances is taken into account to control ship speed in the surge direction. Another power management implementation is found in [37].

In contrast to power management strategies, there are only a few marine studies on shipboard energy management for entire missions. In [26], a predictive controller that uses a short-term prediction scheme has been implemented in an electric tugboat, yielding $9 \%$ fuel consumption reduction when compared to a rule-based EMS. The study also incorporates the $\mathrm{SoC}$ constraints in the optimisation horizon solver. However, mission-scale predictions surpassing the prediction horizon and their effect on optimal fuel consumption were not examined. Furthermore, a comparison with optimal control policies was not present. Huotari et al. [38] takes into account mission-scale predictions and benchmarks the proposed MPC-based controller against an exhaustive solution for a diesel-electric cruise ship power plant case study. This study uses mixed integer linear programming (MILP) as the MPC solver while it also incorporates a 2-stage predictive scheme to provide a mission-scale prediction. Despite the effectiveness of the method in achieving close to optimal results, it is noted that the controller does not incorporate updates on the future disturbances while sailing and the prediction is provided to the solver prior to the mission. A rule-based controller is utilised instead in order to compensate for deviations between the actual disturbances and the initial estimate. In addition, a constraint on the maximum and minimum (dis)charging power of the battery is incorporated in the optimisation problem. This should be effective in protecting the battery from exceeding the minimum $\mathrm{SoC}$ value. However, a constraint on the $S o C$ value at the end of the mission is not present, which is important for optimal performance in charge-sustaining mode.

In an automotive study [34], an implementable MPC framework is developed with near-optimal performance, enabling online updates and utilising information from the ITS for load prediction. This controller is adapted in the present work to design a shipboard MPC framework and address the performance issues of advanced EMS in ships.

\subsection{Aim, Contributions and Assumptions}

The first goal of this research work is to examine how the loading sequence of the whole mission affects the fuel savings of an exhaustive solution found with dynamic programming. This is attained by using partial and full loading sequence information, corresponding to short-term and mission-scale predictions made for the EMS. 
Secondly, this study develops an energy management framework based on MPC that addresses multiple objectives which have not simultaneously been fulfilled by EMS alternatives proposed in the literature. The MPC framework:

1. Deals with battery-induced integral state constraints robustly.

2. Realises potential fuel savings due to mission-scale information.

3. Performs close to the exhaustive DP solution results.

4. Can be readily set to function in charge-sustaining (CS) or charge-depleting (CD) battery mode.

5. Enables real-time adaptation to shipboard updates on the mission-scale disturbance estimation while sailing, rather than using offline tuning of parameters such as the equivalency factor in ECMS, predefined power demand sequences [38] or rule-based tuning.

6. Requires minimal parameter tuning on specific operating profiles enabling deployment on early design stages, with the prerequisite that a model description for the powertrain is available.

This MPC framework has been validated in both CS and CD mode by incorporating the controller in a dynamic Simulink ${ }^{\circledR}$ model of a naval hybrid propulsion powertrain with hybrid power supply, validated in [39].

It is noted that, to factor out the performance of individual long-term and short-term prediction solutions, the study assumes perfect predictors with a fabricated information barrier scheme for the experiments, which will be discussed in more detail in the results segment. For future reference, several alternatives for disturbance prediction found in recent studies are proposed. Long-term predictions can be made by data-driven prediction approaches, such as the one found in [40], where a physics-based machine learning (PBML) model is proposed. The utilization of advanced routing models, such as the one found in [41], can be combined with weather data, navigation aids, the governor's human input, and sensor information to provide highly accurate predictions. For short-term disturbance estimation, several prediction schemes may be used, such as the prediction scheme proposed in [26], neural network approaches, such as the RBF-NN implementation in [34] and autoregressive moving-average (ARMA) models [42].

\section{Materials and Methods}

\subsection{Model Description}

The propulsive plant is described by a set of differential and algebraic equations (DAE) with inequality constraints for the operating limits of the various components. The DAE system is defined by the propulsive layout and by means of fitted equations whose parameters are tuned using experiments on a component level as in [16], either directly from physical measurements or from detailed dynamic simulation models of components. For fuel consumption minimisation, quasi-static models are typically modelled by fuel consumption maps, or fitted functions, as dynamic behaviour is of secondary importance [30]. Most of the formulations for the components have been verified and validated in [16] and the derivations will not be repeated here.

The quasi-static description for the components of a shipboard hybrid power plant can in turn be reused for different hybrid layouts. Following the methodology for formulating a non-linear model description for MPC purposes as in [34], the model description for the hybrid propulsion hybrid power supply configuration in Figure 1 is presented here:

1. The electrical and mechanical nodes of the plant correspond to energy balance equations.

2. For a given disturbance vector, which is typically comprised by the propulsive load, hotel load and shaft speed, the operating setpoints of the components are not uniquely defined due to the degrees of freedom (DoFs) in the system. For example, the propulsive demand can be met by infinite combinations of main engine and induction motor power output levels. The number of indefinite variables in the model description 
corresponds to the DoF in the system and each DoF correspond to an additional system control input.

3. Each component introduces operating constraints which should be explicitly expressed.

4. Finally, since the $S o C$ of the battery must be within its operating constraints, it should be introduced to the system as a state variable.

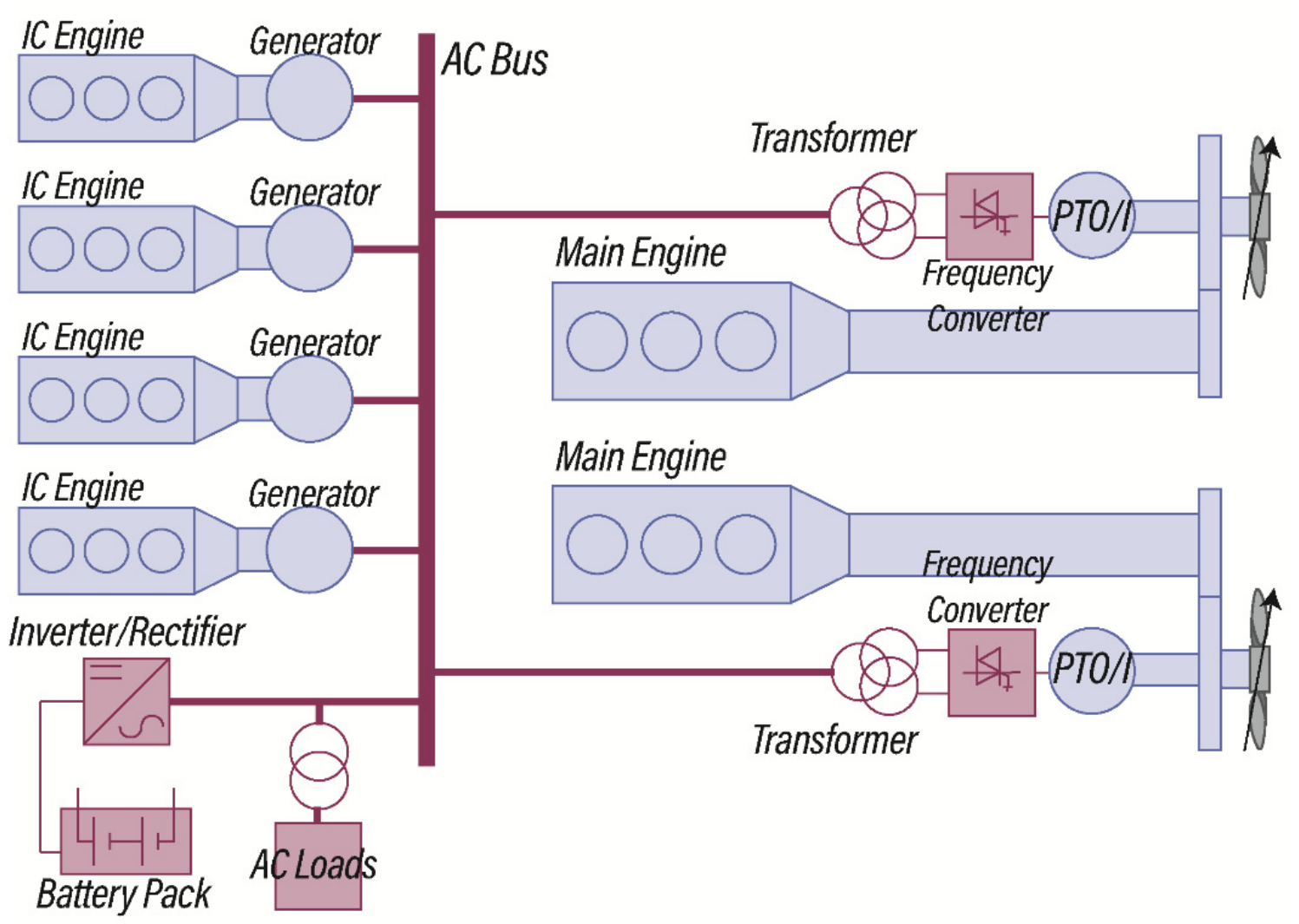

Figure 1. Vessel power plant.

The SoC of a battery cell is defined as the charge in the battery, divided by the cell's maximum charge, $Q(t) / Q_{\text {cell }, 0}$. The derivative yields

$$
\text { So C }=-\frac{I_{\text {cell, bat }}}{Q_{\text {cell }, 0}},
$$

and by discretising with a timestep of $\Delta t$ :

$$
\operatorname{SoC}(t+\Delta t)=\operatorname{SoC}(t)-\frac{I_{c e l l, b a t} \Delta t}{Q_{c e l l, 0}}
$$

where $I_{\text {cell,bat }}$ the current in the battery pack (positive for discharging).

There are several ways to define battery efficiency, categorised in [43] into global and local efficiencies, depending on whether the efficiency is averaged over the entire (dis)charging cycle (energy ratio) or is calculated as a power ratio. Local efficiency varies by both (dis)charging battery power and SoC. Local efficiency is strongly dependent on the (dis)charging battery power, while dependency on the $S o C$ is much weaker [43]. This is the reason why global efficiency is sufficient for CS operation. However, in CD battery mode, the SoC value is depleted at $20 \%$ [16], and in such low values contribution to the battery efficiency is no longer negligible. The battery efficiency is used in EMSs for the estimation of the SoC and small errors are accumulated over time. 
This study uses the battery equivalent circuit found in [16]. However, instead of the global Ragone efficiency, for the reasons above, the electrochemical local efficiency of the battery $\eta_{e c h}$ has been used instead. The electrochemical power of the battery cell is defined as the power of the battery without taking into account the internal losses [43]:

$$
P_{\text {cell,ech }}=V_{\text {cell,open }} I_{c e l l, b a t}
$$

where $V_{\text {cell,open }}$ the open circuit voltage. The electrochemical power $P_{\text {cell, ech }}$ is connected to the battery cell power $P_{c e l l}$, bat with the electrochemical local efficiency:

$$
\eta_{\text {ech }}^{\operatorname{sgn}\left(P_{\text {cell,bat }}\right)}=\frac{P_{\text {cell,bat }}}{P_{\text {cell,ech }}}=\frac{V_{\text {cell, bat }}}{V_{\text {cell,open }}}=f\left(P_{\text {cell,bat }}, \text { SoC }\right) .
$$

The electrochemical efficiency can be expressed as a polynomial function of the power and $S o C$ :

$$
\eta_{\text {ech }}=\left\{\begin{array}{c}
\sum_{i=0}^{2} \sum_{j=0}^{2} d_{i j} \operatorname{SoC}^{i} P_{n}{ }^{j}, P_{n}>0 \\
\sum_{i=0}^{2} \sum_{j=0}^{2} c_{i j} \operatorname{SoC}^{i} P_{n}{ }^{j}, P_{n} \leq 0
\end{array}\right.
$$

where $c_{i j}$ and $d_{i j}$ are fitting parameters for charging and discharging to be determined experimentally, $P_{n}=P_{\text {cell }} / P_{\text {cell, } m a x}$.

A complex expression for the open circuit voltage is used as in [16]:

$$
V_{\text {cell,open }}=\alpha_{1} \cdot e^{\alpha_{2} \cdot S o C}+\alpha_{3}+\alpha_{4} \cdot S o C+\alpha_{5} \cdot S o C^{2}+\alpha_{6} \cdot S o C^{3},
$$

where $\alpha_{i}$ model parameters to be determined experimentally. Combining Equations (3) and (4) while also converting from the pack to the cell:

$$
I_{c e l l, b a t}=\frac{P_{\text {pack,bat }}}{n_{\text {par }} \cdot n_{\text {ser }} \cdot V_{c e l l, o p e n} \cdot \eta_{\text {ech }}^{-s g n\left(P_{b a t}\right)}},
$$

where $n_{\text {par }}$ is the number of cells connected in parallel and $n_{\text {ser }}$ in series. The $S o C$ for every the next time-step now is:

$$
\operatorname{SoC}(t+\Delta t)=\operatorname{SoC}(t)-\frac{I_{\text {cell,bat }} \cdot \Delta t}{Q_{c e l l, 0}}, \operatorname{SoC} \in\left[\operatorname{SoC}_{\text {min }}, S_{\text {max }}\right] \text {. }
$$

Substituting the expression for the $I_{c e l l, \text { bat }}$ into Equation (8) provides a way to calculate the $S o C$ for the next time step.

For non-DC architectures, the battery pack is connected via a static converter (inverter/rectifier) to an AC grid. The battery module current $I_{b a t}, A C$, for the case of a3-phase AC grid, is connected to the battery pack power $P_{b a t, A C}$ with the expression:

$$
I_{b a t, A C}=\frac{P_{b a t, A C}}{V_{\text {line }} p f \sqrt{3}}
$$

where $V_{\text {line }}$ is the line voltage and $p f$ is the power factor of the AC bus.

The associated current losses at the converter, $I_{b a t, c n v, l o s}$, are given by the following quadratic fitted relationship, assumed to stay the same for both converting modes:

$$
I_{b a t, c n v, l o s}=I_{n o m, l o s} \cdot\left(e_{1} I_{n}^{2}+e_{2}\left|I_{n}\right|+e_{3}\right)
$$


where $I_{\text {nom, los }}$ the nominal current losses and $e_{i}$ fitting parameters. Moreover, $I_{n}$ is the normalised current $I_{n}=I_{b a t, A C} / I_{b a t, A C, n o m}$ :

$$
I_{n}=\frac{I_{b a t, A C}}{I_{b a t, A C, n o m}}
$$

The $I_{\text {pack,bat }}$ can then be found as:

$$
I_{\text {pack,bat }}=I_{b a t, A C}+I_{b a t, c n v, l o s} .
$$

Note that $I_{b a t, c n v, l o s}>0$ so that during charging $(I<0)$ the rectifier losses are subtracted from the current input towards the battery, while during discharging $(I>0)$ the inverter losses are added.

The fuel consumption of the diesel generator set can be measured by varying the torque at a constant rotational speed. A cubic approximation is provided using manufacturer's data (as in [16]) as a function of the normalised power output of the generator set, $P_{\text {genset }, n}$ :

$$
\dot{m}_{f, \text { genset }}=k_{\text {genset }} \dot{m}_{f, D G, \text { nom }} \sum_{i=0}^{2} g_{i} \cdot P_{\text {genset }, n}^{i},
$$

where $g_{i}$ positive fitting parameters and $k_{\text {genset }}$ the number of active generator sets at a time. The approximation is a convex function because the second derivative of the fuel consumption is $2 g_{2}>0$, strictly positive. This allows for choosing the optimal number of active generator sets using only the required power output (See Appendix A).

The main diesel engine fuel consumption can be approximated with a polynomial function of the normalised power output $P_{D E, n}$ and engine shaft speed $n_{D E, n}$ :

$$
\dot{m}_{f, D E}=k_{p} \dot{m}_{f, D E, n o m} \sum_{i=0}^{4} \sum_{j=0}^{4} b_{i, j} n_{D E, n}^{i} P_{D E, n^{\prime}}^{j}
$$

where $b_{i, j}$ fitting parameters, $k_{p}$ the number of propulsion trains (assuming one engine per propeller).

The electric machine has been modelled based on a piecewise polynomial fit, where the normalised power losses, $P_{P T O / I, l o s s, n}=P_{P T O / I, l o s s} / P_{P T I, l o s s, n o m}$, of the variable speed drive can be expressed as a symmetric function of the normalised motor speed, $n_{n}$, and torque, $M_{n}$ :

$$
P_{\text {PTO } / I, \text { loss }, n}=\left\{\begin{array}{c}
v_{2} M_{n}^{2}+v_{1}\left|M_{n}\right|+v_{0}, M_{n} \neq 0 \\
0, M_{n}=0
\end{array},\right.
$$

where $v_{i}$ parameters. The power of the electric machine is

$$
P_{P T O / I}=\left(T_{n o m} N_{P T O / I, n o m}\right) 2 \pi M_{n} n_{P T O / I, n}
$$

with $T_{n o m}$ and $N_{n o m}$ as the nominal torque and shaft speed, correspondingly, and $n_{P T O / I, n}$ the normalised PTO/I shaft speed. If for power-take-off, $P_{P T O / I}<0$, and for power-take-in, $P_{P T O / I} \geq 0$, the power before the PTO/I gearbox is:

$$
P_{\text {drive }}=P_{P T O / I}-\left|P_{P T O / I, l o s s}\right|,
$$

while the power at the $\mathrm{AC}$ grid is:

$$
P_{P T O / I, A C}=-P_{P T O / I}+\left|P_{P T O / I, l o s s}\right| \cdot
$$

The gearbox ratio between the propeller shaft and the PTO/I, and the main engine and the propeller shaft is:

$$
i_{G B, \text { drive }}=\frac{n_{P T O / I}}{n_{S}}
$$




$$
i_{G B, D E}=\frac{n_{D E}}{n_{S}} .
$$

The mechanical power balance can be expressed as

$$
\eta_{G B, D E} P_{D E}+\eta_{G B, \text { drive }} P_{\text {drive }}=\frac{P_{\text {prop }}}{k_{p}},
$$

where $P_{\text {prop }}$ is the total propulsive demand and $\eta_{G B}$ is the gearbox efficiencies for the PTO/I and the main engine shaft. The power quantities have been multiplied with their nominal values. The power balance at the $\mathrm{AC}$ grid is

$$
k_{\text {genset }} P_{\text {genset }}+k_{p} P_{P T O / I, A C}+P_{b a t, A C}=P_{\text {hotel }},
$$

where $P_{\text {hotel }}$ is the hotel power demand on the AC grid and the $k_{\text {genset }}$ the active generator sets at each instant.

Since the model is quasi-static, the dynamic behaviour of the propulsion system due to waves, propeller shaft inertiae, and propeller pitch are neglected. Thus, the propulsive power demand $P_{\text {prop }}$ and the propeller shaft speed $n_{p}$ can be separate disturbances to the system. A separate module that generates these disturbances from e.g., the sea state and the ship speed can be used.

The operating envelope of the main engine is divided into three different regions, the power limit, $n_{2} \leq n_{D E} \leq n_{\max }$, the torque limit, $n_{1} \leq n_{D E} \leq n_{2}$, and the turbocharger limit, $n_{\min } \leq n_{D E} \leq n_{1}$. The last limit is expressed in terms of maximum power as a function of the shaft speed:

$$
P_{D E \text {, max }, T B}=\beta_{1}+\beta_{2} n_{B}{ }^{2},
$$

where $\beta_{1}, \beta_{2}$ parameters. A safe factor can be used in the controller to ensure that the operating limits are not violated during operating point transitions, and the engine is stable.

The per cell maximum continuous current of the battery is $I_{\max }$, while the cell capacity is $Q_{0, \text { cell }}$. This gives a maximum C-rate of $C_{\max }=I_{\max } / Q_{0, \text { cell }}$ per cell. For this C-rate, the power output $P_{\text {cell,max }}$ can be measured, resulting in a total power output of $P_{b a t, \max }=n_{s e r} n_{p a r} P_{b a t, \max }$. Furthermore, there is a limit on the battery state of charge, $S_{0} C_{\min } \leq S o C \leq 1$. It is important to note that the latter is an integral constraint on the state.

A minimum value for the torque $M_{n, \min }$ of the electric machine is active, or zero when the electric machine is disengaged.

Finally, the power from each generator set is $P_{\text {genset,min }} \leq P_{\text {genset }} \leq P_{\text {genset,max }}$ or zero when the generator set is off.

\subsection{Energy Management Strategy Framework}

The ship dynamic behaviour can easily be written with the system description of the following form:

$$
\begin{aligned}
& \text { So C }=f\left(S o C, I_{n}\right) \\
& \vec{y}=g(S o C, \vec{u}, \vec{r}),
\end{aligned}
$$

where $\mathrm{SoC}$ is the state variable, $y$ the system output vector, $u$ the control input vector and $r$ the disturbance vector, which are:

$$
\begin{gathered}
\vec{y}=\left[\begin{array}{c}
\dot{m}_{f, D E} \\
\dot{m}_{f, \text { genset }}
\end{array}\right], \\
\vec{u}=\left[\begin{array}{c}
M_{n} \\
I_{n}
\end{array}\right],
\end{gathered}
$$




$$
\vec{r}=\left[\begin{array}{c}
n_{s} \\
P_{\text {prop }} \\
P_{\text {hotel }}
\end{array}\right]
$$

The algebraic power balance in Equations (21) and (22) allow for the system output to be calculated. Note that the physical description contains non-linear expressions, e.g., due to the (dis) charging of the batteries. The operating constraints presented previously are part of the system description.

A non-linear constrained optimal control problem (OCP) is introduced where the objective is to find the control input at every time instant which minimises the cost function $J$ :

$$
J(\vec{u}(t))=\varphi\left(\operatorname{SoC}\left(t_{f}\right)\right)+\int_{t_{0}}^{t_{f}}\left(\dot{m}_{f, D E}+\dot{m}_{f, \text { genset }}+G\right)
$$

where the fuel consumption terms and the $G$ term are functions of the control input vector, the state, and the time. Term $\varphi$ penalises the end state $S o C$ and term $G$ penalises the state variable. $t_{f}$ and $t_{0}$ the end and start instants. Discretising with respect to time, the OCP then requires a control input policy $\pi^{*}=\left\{\boldsymbol{u}_{1}, \boldsymbol{u}_{2}, \ldots, \boldsymbol{u}_{N}\right\}, \boldsymbol{u}_{k} \in \boldsymbol{U}$ so that:

$$
\begin{gathered}
\pi^{*}=\underset{\pi \in \Pi}{\operatorname{argmin}}\left\{J_{\pi}\right\} \\
+\sum_{k=1}^{N}\left(\dot{m}_{f, D E, k}\left(\vec{u}_{k}\right)+\dot{m}_{f, \text { genset }, k}\left(\vec{u}_{k}\right)+\gamma_{k}\left(S_{N o C_{k}}\right)\right)
\end{gathered}
$$

where the constraints on SoC are enforced with term $\gamma_{k}$. Time steps $t=t_{0}+0 \Delta t, t_{0}+$ $1 \Delta t, \ldots, t_{0}+N \Delta t$ are denoted as $1,2, \ldots N$. Every control action results in the state of the next time step. Further discretising the state and control input variables into $N_{S o C}$ and $N_{u}$ values, correspondingly, allows for the OCP to be solved with dynamic programming DP. Using the MATLAB ${ }^{\circledR}$ generic DP solver in [44], the method has been followed in a number of studies for automotive applications to minimise $J[30,34,45]$.

The momentary fuel consumption for the generator set and the main engine is given in Equations (13) and (14), correspondingly, and is present in the objective function of the OCP in Equation (31). The genset fuel consumption is only dependent on the demanded power from the generator $P_{\text {genset }}$ (see Appendix A), which is in the algebraic Equation (22). The main engine fuel consumption depends on the demanded main engine power, $P_{D E}$, and the shaft speed $n_{s}$, which is one of the three disturbances to the system. For a valid solution to the model description with given disturbances, the value for the PTO/I power is found from Equation (16) for torque control input, $M_{n}$, and the battery power is found from Equation (9) for battery current control input, $I_{n}$, are found. Together with the disturbances for the hotel, $P_{\text {hotel }}$, and propulsive power demand, $P_{\text {prop }}$, it yields two Equations (21) and (22) with two unknowns: the power of the main engine and the power of the generator set. Then from Equations (13) and (14) the solution can be evaluated with respect to the objective function in Equation (31). The solver finds the values for the control inputs which minimise the momentary fuel consumptions, summed up for all time steps.

Operating limits on the components of the ship's hybrid powerplant and the integral constraints on the SoC need to be applied effectively. The DP solver is using only the defined set of the discretised control input vector $\boldsymbol{U}_{k}$. It also includes the penalising terms $\varphi$ and $\gamma$ to apply constraints on the state. This allows for robust behaviour, ensuring all constraints are enforced.

In -MPC-, a series of OCPs are solved for subsequent time intervals or control horizons $T_{c}=N_{c} \Delta t$. At each time step $k$,where $t_{k}=k \Delta t$ the state variable $x_{k}$ is sampled from the physical system. The disturbance vector $\boldsymbol{r}_{k, k+N c}$ for the horizon needs to be known or estimated in advance. Each OCP solution is found by feeding the above to the system description, yielding the optimal control input policy for the horizon $\pi_{k, k+N c}^{*}=\left\{\boldsymbol{u}_{k}, \boldsymbol{u}_{k+1}\right.$, 
$\left.\ldots, \boldsymbol{u}_{k+N c}\right\}$. However, only the first control input vector $\boldsymbol{u}_{k}$ is given to the physical system, while the rest are discarded and the procedure is repeated for the next time step $k+1$, sampling the next state variable $x_{k+1}$ from the system.

The advantages of MPC are identified in [29]. MPC is capable of using multiple variables for the state and control inputs; it is also suitable for handling binary variables and non-linear systems. For non-linear systems, the term non-linear MPC is used in the literature [46]. Applicability is promising for shipboard hybrid systems, where more components are present compared to automotive hybrid powertrains, and (dis)connecting generator sets or (dis)charging the battery module introduces non-linear equations. Moreover, MPC is inherently able to use new predictions for the disturbance vector $r$ whenever available, because it fully recalculates the $\mathrm{OCP}$ at every time step.

Conventional MPC originates from the process industry where it is important to use a setpoint tracking term to penalise deviations from the reference system output or state at each stage of the OCP [29]. However, the objective of an EMS fits the description of economic or performance optimisation and can therefore be addressed by formulations described in the literature as economic MPC [46,47]. These formulations drop the conventional setpoint tracking term and instead optimise for an economic objective by use of a performance term (first term of Equation (29)) [48,49]. The setpoint tracking is then done with a terminal constraint or penalty (second term of Equation (29)). The reader is referred to [46] for an overview on the stability and optimality of economic non-linear MPC.

Sun et al. [34] in a study for automotive vehicles, use a non-linear MPC approach as a compromise between DP and ECMS for energy management. On one hand, DP requires the load profile and duration to be known in advance, thus, it is predominantly used for benchmarking or tuning other EMS. On the other hand, ECMS performs well when information is given only on the present time instant, however, tuning of the equivalence factor, which depends on the loading profile, is not a trivial tasks and needs to be done in advance. This introduces a loading-sequence-specific control design overhead. Adaptive implementations (A-ECMS) use only a set of equivalence factors and the implementation in [16] failed to perform well for loads that differ for the profiles used for tuning.

Following the framework design found in [34], the proposed controller MPC framework is comprised by two modules, namely the reference trajectory generation (RTG) module and the non-linear MPC module (top two blue blocks in Figure 2). Both modules solve a discrete-time finite horizon non-linear OCP with DP in order to minimise the fuel consumed in the form of an integral objective function, given by Equations (30) and (31). In predefined time intervals, the RTG module is initiated and fed with the available remaining mission load estimation as the disturbance vector input $\boldsymbol{r}_{\text {mission }}$. This future update is shown in Figure 2 with the arrow from the mission-scale disturbance estimation at the top left to the RTG module at the top right. Every time a new future update on the remaining mission disturbance vector is fed to the framework, this also updates the RTG solution. From the RTG solution, a mission reference state trajectory for the battery $S_{0} C_{r e f}(t)$ is computed. The MPC module is instead using a short term prediction $\boldsymbol{r}_{\text {horizon }}$ and is solving a new OPC for a defined control horizon at every control time-step $t_{k}$. Using an end-state constraint (ESC) for the $S o C$ at the end of each horizon, the MPC solution is guided towards the solution generated by the RTG module:

$$
\left|\operatorname{SoC}_{M P C}\left(k+N_{c} \Delta t\right)-S_{o} C_{r e f}\left(k+N_{c} \Delta t\right)\right| \leq E,
$$

where $E$ is the parameter in the ESC tuned to allow for feasible solutions in case of disagreement between the short-term MPC solution and the mission-scale solution by the RTG module. The end-state constraint is enforced with the $\varphi$ term of Equation (31). 


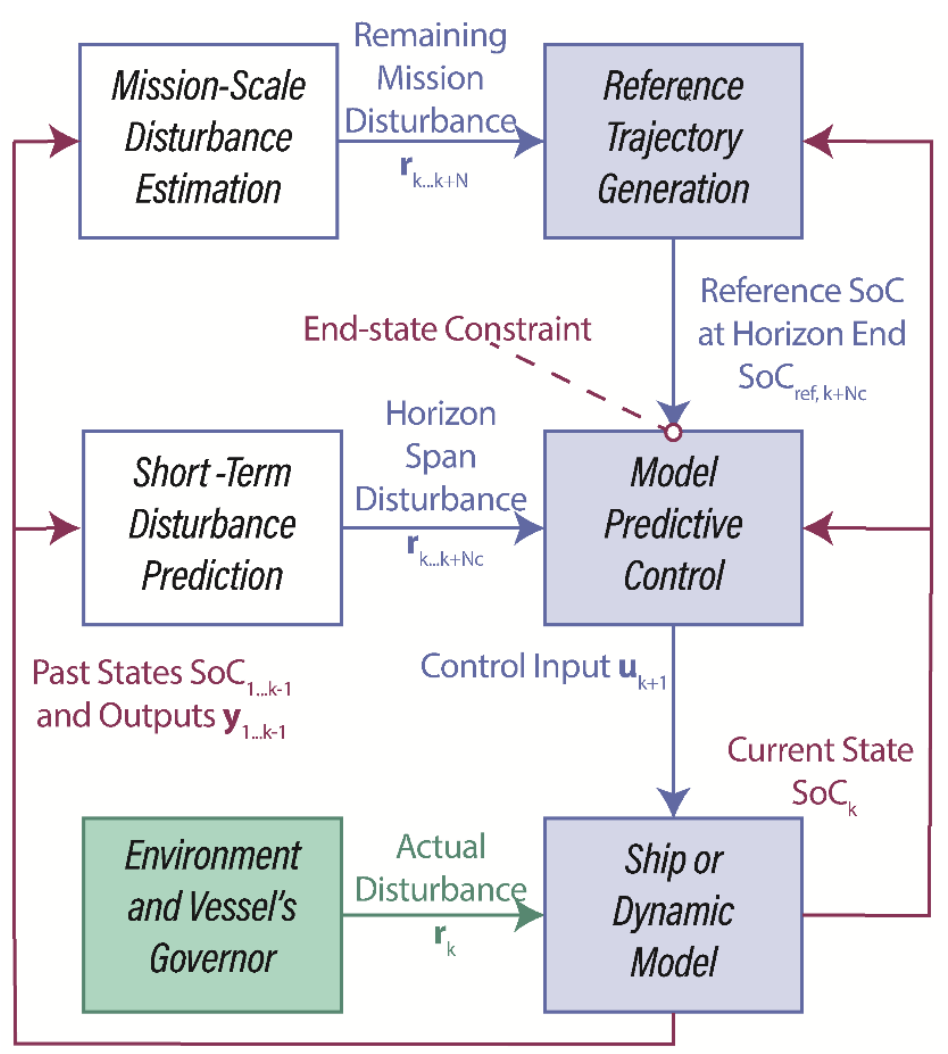

Figure 2. The MPC framework.

In both the RTG and MPC modules the behaviour of the propulsive plant is described by the quasi-static model description given at the beginning of this chapter.

By using two different time-scales for the estimations, mission-scale information (e.g., captain's input, weather and routing data), can be combined with a short-term disturbance estimation scheme, examples of which can be found in $[26,34,42,50,51]$. The use of the quasi-static model in the MPC module provides past values of the state and the system outputs that may enhance the performance of the estimation scheme. The present study uses a perfect prediction scheme for both the mission-scale and the short-term, so that the performance of the scheme does not interfere with benchmarking the performance of the proposed MPC framework.

\section{Results}

\subsection{Model Description Tuning and Verification}

The MPC framework was validated by incorporating the controller in a dynamic Simulink ${ }^{\circledR}$ model of a hybrid power plant of a naval vessel provided by Damen Naval BV (Figure 1). For that reason, the parameters of the system description have been formulated using measurements from the model, whose details and validation are mostly covered [43], except from the electric machine, which has been simplified here to the same polynomial in Equation (15).

The telegraph position, $T g$, connects to the virtual shaft speed by the equation $N_{\text {virt }}=\left(N_{\text {virt }, \text { max }}-N_{\text {virt,min }}\right) T g+N_{\text {virt,min }}$, where $N_{\text {virt,min }}$ and $N_{\text {virt,max }}$ are the min and max virtual shaft speed limits. The virtual speed is connected to the propulsive load and actual shaft speed for a fixed combinator curve. An interpolated fit has been chosen, shown in Figure 3. It has been used to generate the disturbance for the shaft speed and the propulsive load from the telegraph position. 


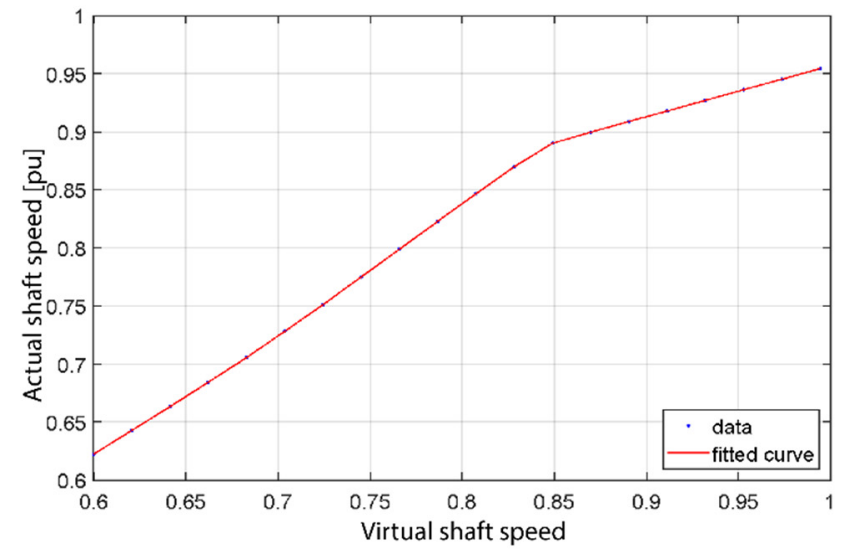

(a)

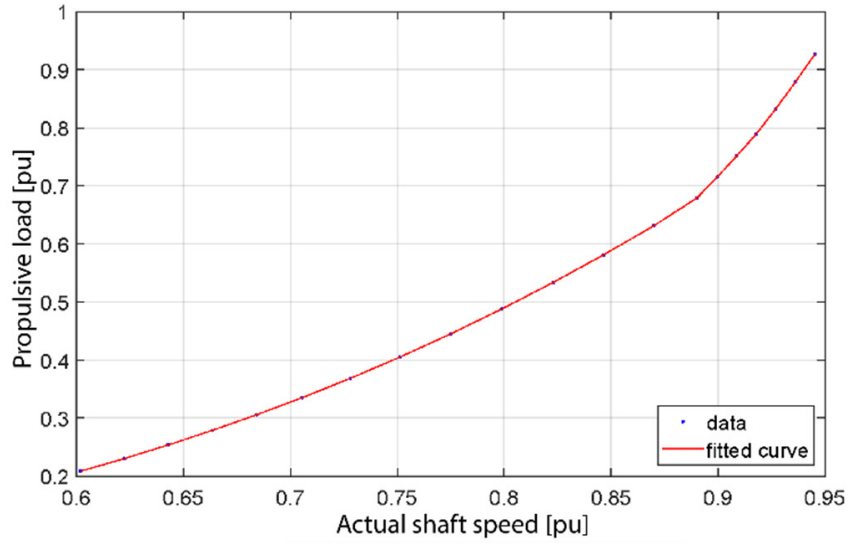

(b)

Figure 3. Interpolated fit connecting virtual shaft speed to (a) the actual engine speed and (b) the propulsive load.

In Table A1 the parameters of the vessel's power plant are given. On a component level, Figures A1-A3 present the fitted results for the electrochemical efficiency of Equation (5) and the main engine consumption of Equation (14). The Simulink ${ }^{\circledR}$ model uses a simple polynomial expression for fuel consumption of the generator set as in Equation (13) so the reduction is trivial. The layout of the hybrid propulsion hybrid power supply power plant is given in Figure 2.

For the electrochemical efficiency of the battery, the effect of the state of charge is observed in Figures A1 and A2 but is more pronounced in the case of cell discharging. The biggest fitting error is observed in Figure A2 with a maximum value of $0.7 \%$, at the region where the state of charge is above 0.95 and for a discharging power above $40 \%$. The residuals for charging are shown in Figure A1, with the biggest fitting error of $0.7 \%$ occurring at the zone where the charging power is above $90 \%$.

The bottom plot of Figure A3 includes the envelope boundaries and shows that the maximum residuals are observed alongside the operating limits of the engine, but do not exceed the 0.008 mark.

The fitted equations for the main engine (Equation (14)) and the battery cells (Equation (5)) are normalised in order to ensure that the fit is as accurate as possible. The corresponding nominal values for the normalised quantities are found in Table A1.

The model description has been verified offline by plotting the results of the same loading profile of total duration of $3000 \mathrm{~s}$ against their Simulink ${ }^{\circledR}$ model counterparts, as shown in Figure 4. For positive values of the battery power in Figure $4 \mathrm{~b}$ the charge of the battery is depleted, shown in Figure 4f, as described in Equations (6)-(8). For this integrated verification case the setpoints do not yield an extensive charging period for the battery. However, the battery charging mode is verified also on a component basis, an important step for accurate SoC tracking, as it is later shown in Section 3.4 that the proposed framework yields extensive charging periods (see Figure 8d). The offline and online behaviour have their biggest difference of $-4.1 \%$ for the diesel generator power around the $800 \mathrm{~s}$ mark and for a relatively short duration of $200 \mathrm{~s}$. Apart from this region, the difference is well below $1 \%$ and it is concluded that the model description is accurate enough to replicate the Simulink ${ }^{\circledR}$ model. It is clarified here that in this section only a model verification is presented and no controller has been implemented in the Simulink ${ }^{\circledR}$ model. That is, the same control input and disturbance vector sequences were fed to both the model and its reduced quasi-static model description, comprised of all components described in the beginning of this section. 


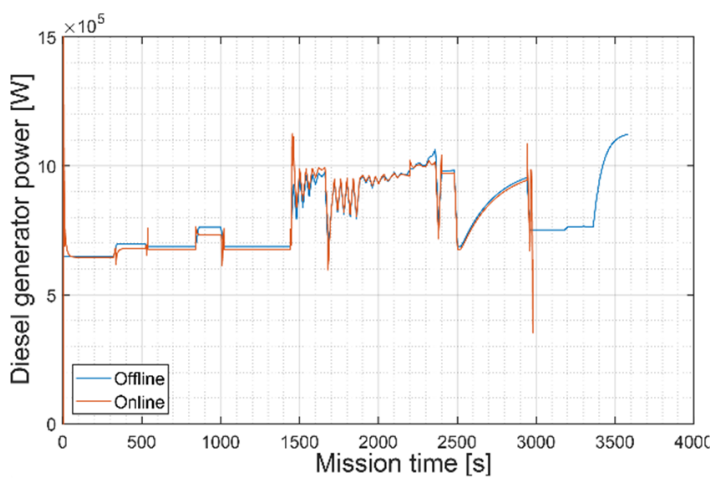

(a)

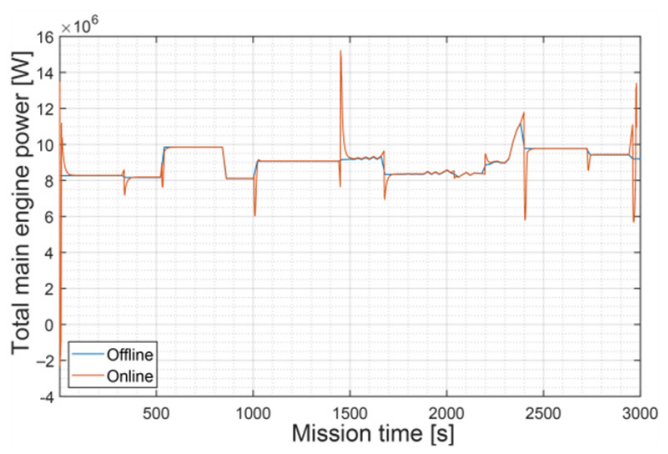

(c)

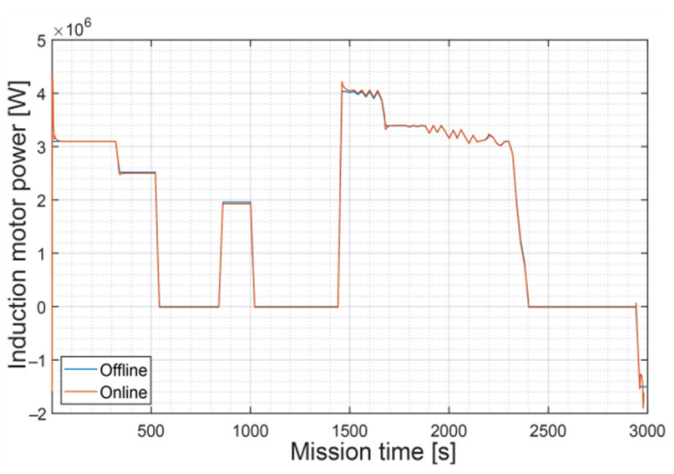

(e)

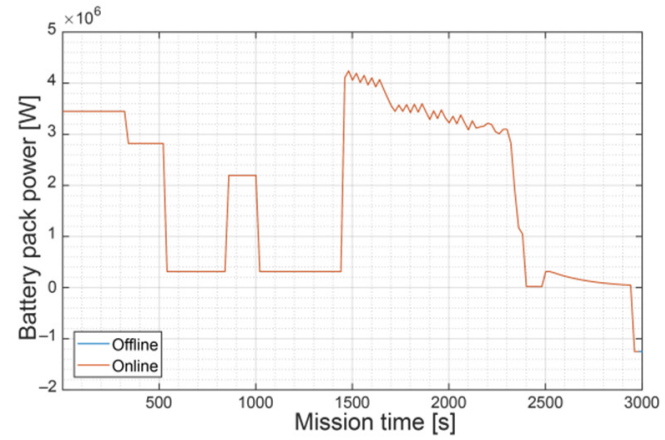

(b)

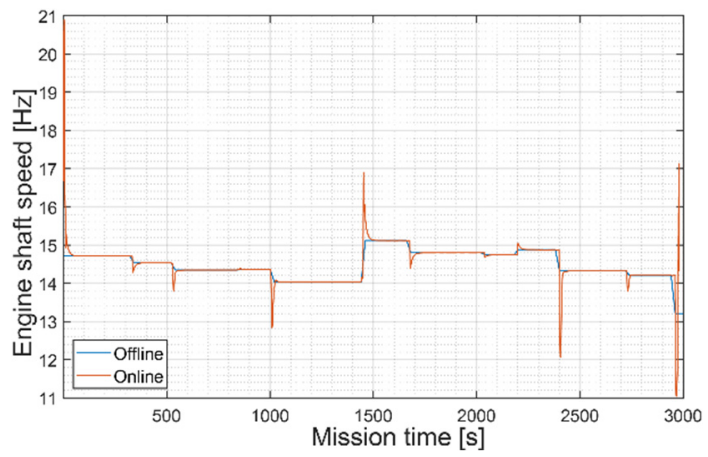

(d)

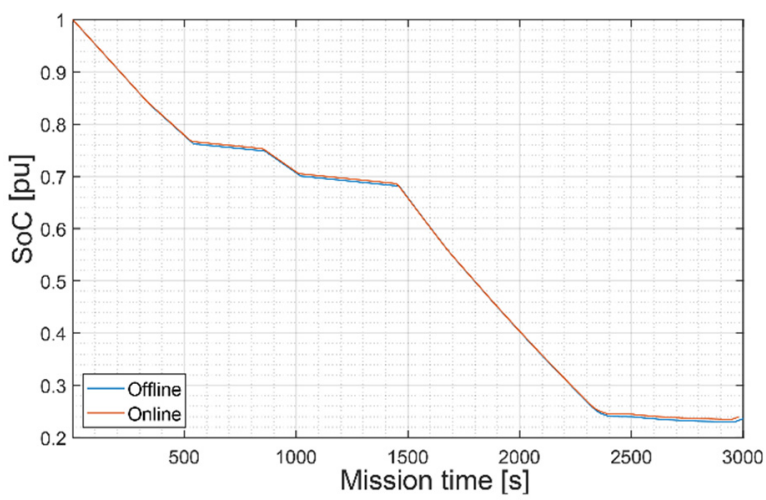

(f)

Figure 4. Verification of the model description (blue line) by comparison with its Simulink model counterpart (red line). Presented here are the (a) diesel generator power (b) battery pack power (c) total main engine power (d) engine shaft speed (e) induction motor power and (f) state of charge trajectory.

\subsection{Verification of the Reference Trajectory Generator Module}

The MPC framework was first implemented offline in order to select suitable values for the solver parameters and the MPC. Both the RTG and MPC modules of the framework use the generic MATLAB ${ }^{\circledR}$ DP solver [45] to solve the OCPs.

Regarding the numerical details, the discretisation of the state and control input variables was found to be adequate at $N_{x}=N_{u}=41$, above which not much reduction in fuel consumption was observed, while the computational load increased considerably. The number needs to be odd so that the mid setpoint of each variable can be zero, while the variables are normalised. The solver's boundary line method was used, which provides better accuracy for the discretisation number. The non-fixed grid option was selected and the time step of the solver was set to $20 \mathrm{~s}$. 
The RTG module underwent several qualitative verification tests: A base case of the telegraph position, an increased position by $10 \%$, and a decreased position by $10 \%$ were compared to check whether the fuel consumption changed consistently. The results are shown in Table 1. The telegraph position is connected linearly to the propeller speed (until $\left.0.9 n_{p, \max }\right)$ and the propeller speed is connected almost linearly to the propulsive demand (until $0.68 P_{\text {prop, } \max }$ ) due to the controllable pitch propeller (CPP), as shown in Figure 3. The specific fuel oil consumption is fairly uniform (less than $7 \%$ difference between minimum and maximum value in Figure 5a). Thus, an increase in fuel consumption is expected with $10 \%$ increase in the telegraph position and vice versa, since that corresponds to more than a $20 \%$ increase/decrease for the power demand.

Table 1. RTG load consistency check.

\begin{tabular}{ccc}
\hline Profile/Telegraph Position & Fuel Consumption $[\mathrm{kg}]$ & Difference $[\%]$ \\
\hline Base & 1974.3 & \\
$-10 \%$ & 1908.1 & -3.35 \\
$+10 \%$ & 2085.5 & +5.63 \\
$50 \% \mathrm{P}_{\mathrm{DE}, \mathrm{nom}}$ & 2055.1 & +4.09 \\
$50 \% \mathrm{~T}_{\text {nom }}$ & 2056.7 & +4.17 \\
\hline
\end{tabular}

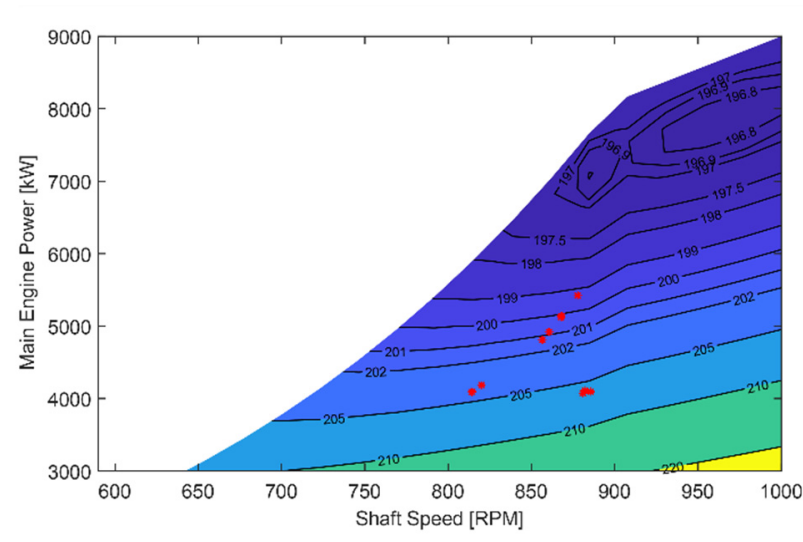

(a)

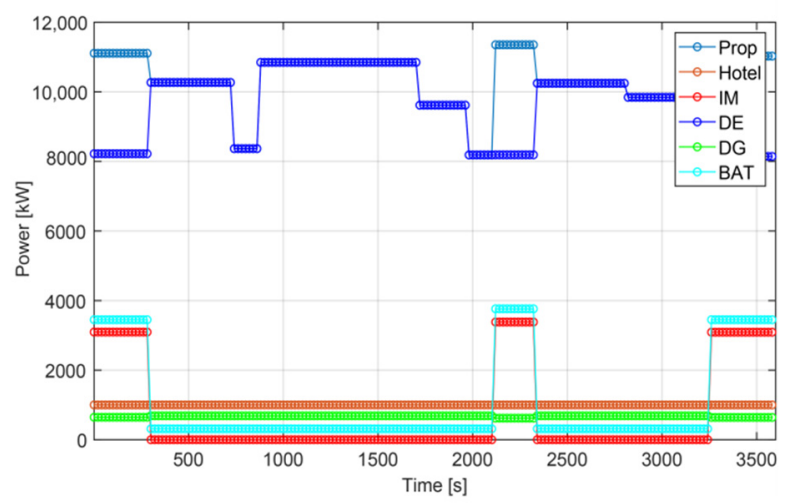

(b)
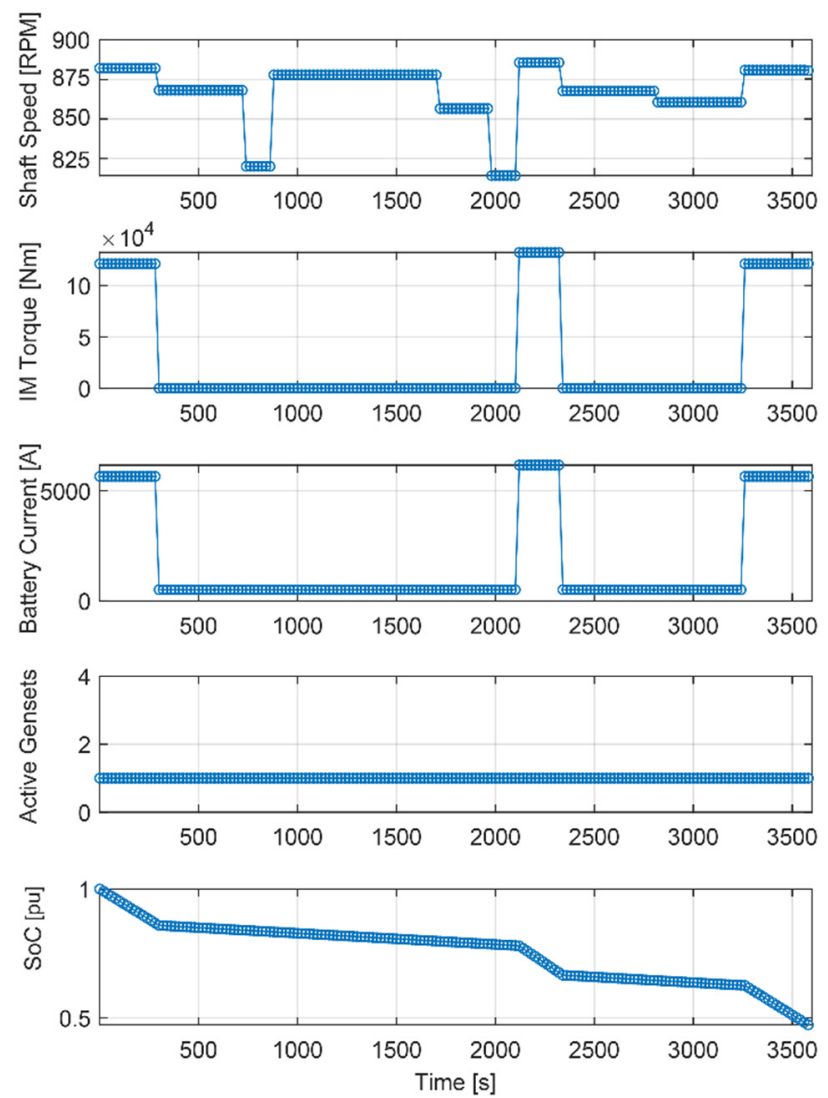

(c)

Figure 5. Verification of the RTG module: Scenario with stricter engine operating boundaries. (a) Main engine setpoints resulting from the control input plotted on the SFOC $[\mathrm{g} / \mathrm{kWh}$ ] contour plot; (b) trajectories of the power output of the various powertrain elements together with the propulsive and hotel power demand; (c) trajectories of the shaft speed, the control inputs (induction machine torque and battery current), the number of active generator sets, and the SoC of the battery pack. 
The second test introduces narrower operating boundaries for the components of the power plant. The minimum engine power has been moved from $45 \%$ of the nominal value to $50 \%$, resulting in a consistent increase in fuel consumption. Likewise, an increase in the minimum torque for the PTO/I also increases fuel consumption.

Figure 5 includes a series of plots that show how the various quantities of the components evolve for the increased minimum engine power value. It is noted that not all of the battery charge is used (as opposed to the base case) because the minimum main engine power plus the minimum PTI power is higher than the propulsive demand, meaning that only in peak propulsive power demand regions the PTI can be activated to further deplete the battery.

\subsection{Verification of the Model Predictive Control Module}

At the end of Section 2.2 an overview of MPC is provided. The implementation of the MPC module for this case study is solving an OCP for subsequent control horizons using a DP solver with an ESC at the end of each horizon. In more detail:

1. The state is the battery $S o C_{k}$ and it is sampled from the Simulink ${ }^{\circledR}$ model of the propulsive plant at each time step $t_{k}$ and used as the initial $S o C$ for the OCP.

2. The disturbances to the system are the shaft speed, propulsive power demand, and hotel power demand. The predicted values for each disturbance and for the scope of each horizon are provided to the OCP at each time step $t_{k}$.

3. The $S o C_{M P C}$ at the end of the horizon $t_{k}+N_{c} \Delta t$ is constrained by the $S o C_{r e f}$ of the global solution at the same time-step. This is the ESC of Equation (32).

4. The DP solver is utilised to provide the solution to the OCP above for the control horizon. The control inputs to the system are the normalized battery current $I_{n}$ and electric machine torque $M_{n}$. The resulting control input vector for the next time step $u_{k+1}$ is fed to the system and the control input vectors for the rest of the time-steps, $\boldsymbol{u}_{k+2} \ldots N_{c}$, are discarded.

5. At the next time-step the MPC module samples the next $S o C$ and iterates the procedure.

Before implementing the MPC module in the Simulink ${ }^{\circledR}$ model of the propulsive power plant, the parameters in the MPC code are tuned offline so that the generated control inputs agree with the control inputs of the global solution, which is the DP solution for the full mission, provided online by the RTG module. In this offline verification, the SoC reads the initial state from the results of the global solution at each time-step. The goal is to ensure that the OCP solution with an ESC at the end of the control horizon yields the same control inputs with the global solution.

The ESC parameter for the MPC module was found offline by decreasing the value until the load profile provokes an infeasibility error. For $E=0.01$ the framework is stable with 41 grid elements $\left(N_{u}=N_{x}=41\right)$, while $E=0.07$ can be used for 61 grid elements, and $E=0.05$ for 81 . An analysis of the computational cost of the DP solver used by the MPC framework in this study can be found in [44]. The MPC module control horizon was found offline by starting at the short horizon of only two time steps (40 s) and increasing until the control inputs from the MPC module's OCP converge to those from the RTG module. It was found that a horizon of $600 \mathrm{~s}$ yields optimal response with no instabilities for both step-up and step-down load sequences (Figure 6). The prediction horizon has been chosen to be the same as the control horizon. 

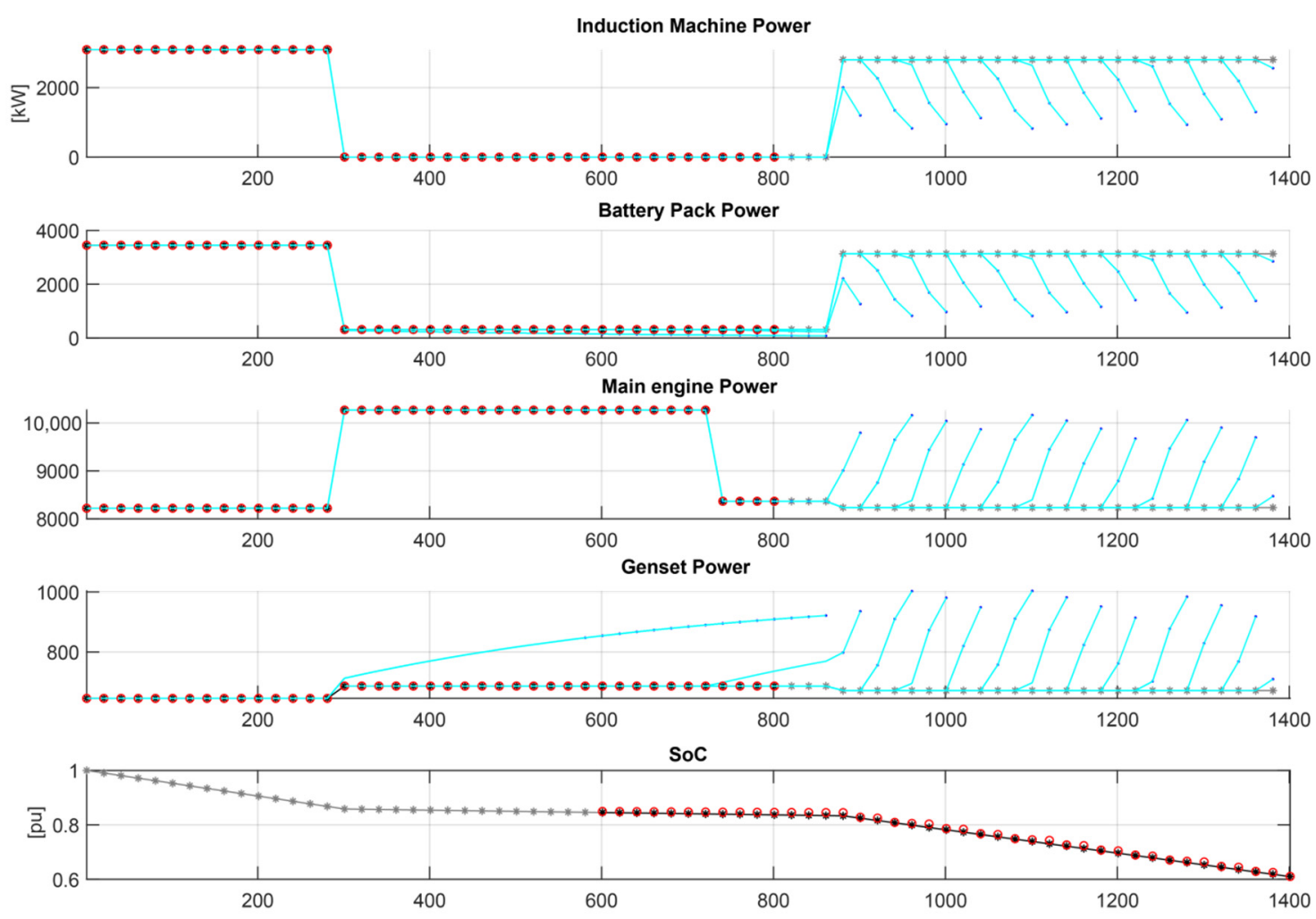

Figure 6. Verification of the MPC module, the setpoints of all horizons are indicated (cyan), together with the implemented setpoints at each time-step (red circles), and for the state of charge the value at the end of the horizon (red circles) is plotted against the value from the RTG (black stars).

\subsection{Validation of the Model Predictive Control Framework}

The validation of the MPC framework is done by incorporating the controller in the Simulink ${ }^{\circledR}$ model, using lvl-2 custom S-functions. A series of realistic telegraph trajectories, generated by a probability density function from historical data, was provided by Damen Naval BV for the vessel. Using the combinator curve presented in Section 3.1, these telegraph trajectories correspond to the disturbances for the propulsive load and the shaft speed. The hotel load power demand has been constant at $1000 \mathrm{~kW}$.

The above loading sequences were spliced together to construct two different scenarios, referred to as Profiles 1-2. The profiles are used in an information barrier scheme which has been devised for the validation of the MPC framework: Two online optimal DP controllers are being fed the same disturbances with the MPC framework controller. At a certain time-step, called the information barrier point (IBP), the telegraph trajectory changes from the initial prediction to the actual trajectory (solid and dashed lines, respectively, shown for profiles 1 and 2 in Figure 7):

- The first online DP controller has perfect information about the disturbances, including the change at the IBP. This means that it is the optimal controller and calculates the control inputs for the telegraph trajectory spliced at the barrier point.

- The second online DP controller solves for the initial prediction until the IBP, where it recalculates the control inputs for the actual trajectory.

- The MPC framework's RTG module is updated with the actual trajectory at the update point, which is before the IBP. 


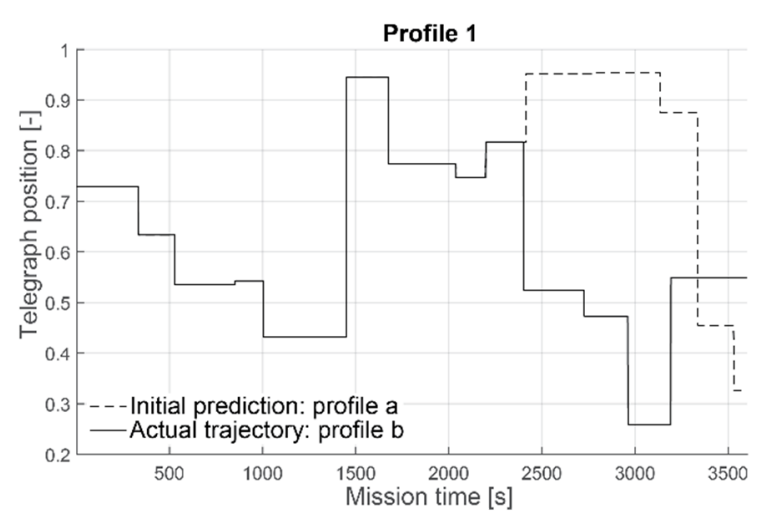

(a)

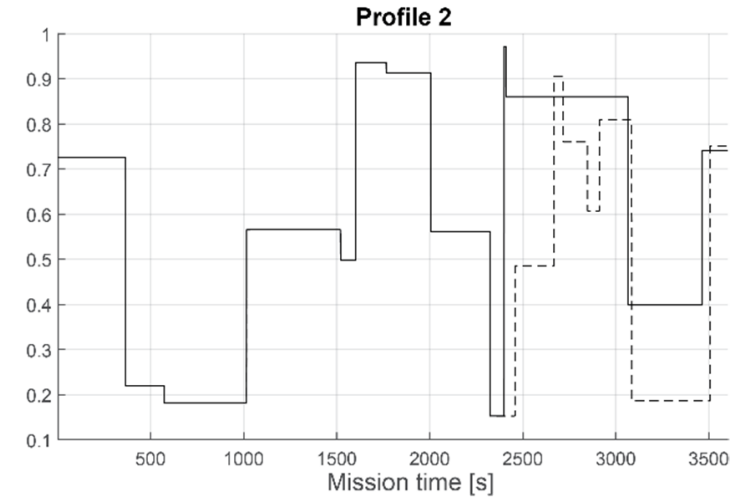

(b)

Figure 7. Telegraph initial and actual trajectories for (a) Profile 1 and (b) Profile 2.

At the final horizon, the MPC framework can either start diminishing its horizon or use the last calculated control inputs from its RTG module. The first option should be preferred. However, it has not been implemented here. For this reason, the final horizon area is not included in the online simulation, resulting in comparison problems when the optimal and barrier DP controllers have not used the same amount of battery charge at the end of the online simulation. Offline simulations with the reduced model descriptions are included to help with interpreting the results. First, the results for the CD mode will be presented, were the end SoC is free to terminate anywhere within [0.2 1], and then the CS mode results will be presented, where the $S o C$ starts at 0.9 and can only terminate with a value in [0.89 0.91].

Table 2 shows the results for CD battery mode. For profile 1, not all of the battery charge is depleted by the barrier controller, and for profile 2, no such effect takes place. The barrier benchmark controller optimally solves a control problem twice: the first time based on the full initially predicted trajectory up until the IBP at $t=2400 \mathrm{~s}$, after which it solves a second time, now for the actual trajectory (remaining mission). The optimal controller solves only once for the actual trajectory. The MPC framework has an information advantage compared to the barrier controller due to the update point at $t=600 \mathrm{~s}$, however, its optimality is not guaranteed and is being benchmarked.

Table 2. Fuel consumption results; in parenthesis the offline results at the end of the final horizon.

\begin{tabular}{ccccc}
\hline & \multicolumn{2}{c}{ Profile 1 } & \multicolumn{2}{c}{ Profile 2 } \\
\cline { 2 - 5 } & $\begin{array}{c}\text { Fuel Consumption } \\
{[\mathbf{k g}]}\end{array}$ & Difference [\%] & $\begin{array}{c}\text { Fuel Consumption } \\
{[\mathbf{k g}]}\end{array}$ & Difference [\%] \\
\hline \multirow{2}{*}{ Optimal } & 1787 & -4.85 & 1758 & 0.00 \\
& $(1961)$ & $(-3.44)$ & $(1949)$ & $(-0.20)$ \\
Barrier & 1878 & & 1758 & \\
MPC & $(2031)$ & -3.57 & $(1953)$ & +2.28 \\
\hline
\end{tabular}

It is noted here that the consumption reduction of the MPC framework compared to the barrier controller is attributed to the information advantage described above. However, even if there is no such consumption reduction, the framework's performance should be further assessed for its robust behaviour (i.e., yielding a feasible control policy while satisfying all constraints) and for its consumption when compared to the optimal controller.

In Figure 8, in the plot for the online simulation of Profile 1, the MPC framework SoC trajectory (blue) starts to follow the optimal controller SoC trajectory (red) after the update point at $t=600 \mathrm{~s}$. This is the point where the RTG module of the MPC framework solves for the updated actual trajectory and provides the new reference to the MPC module of the framework. In the case of the MPC framework, the update for the trajectory occurs 
so that the controller is able to deplete the battery in time, while the late informed barrier controller (yellow) finishes the mission with some "trapped" battery charge. The offline results in Table 2 and Figure 8 also show the effect clearly.

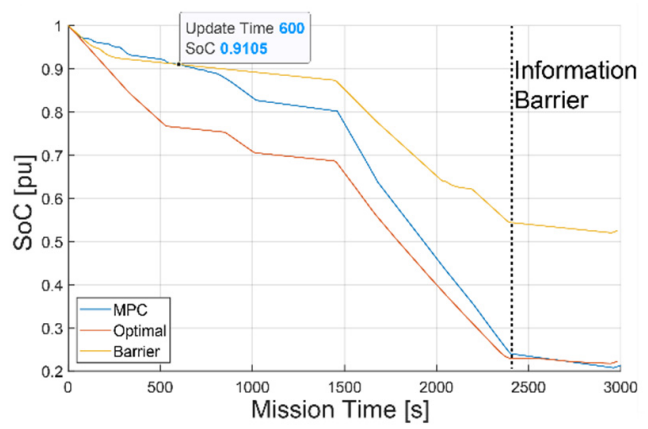

(a)

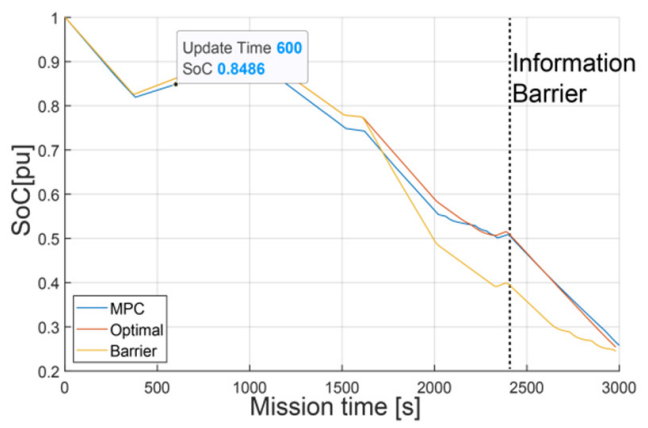

(c)

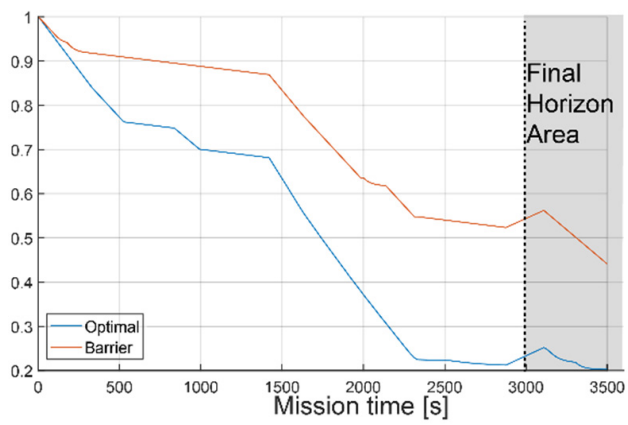

(b)

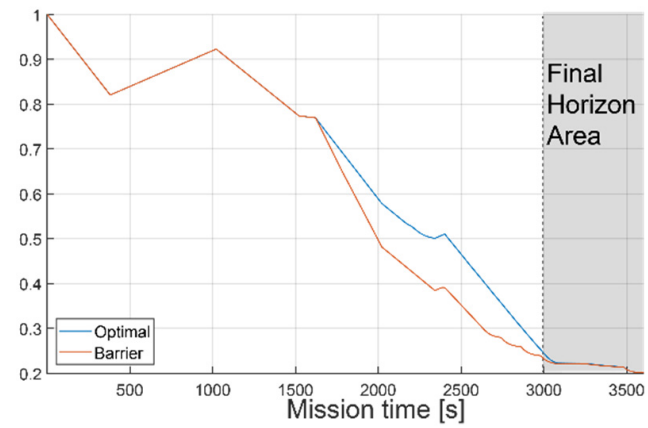

(d)

Figure 8. Comparison of MPC framework against benchmark controllers for charge-depleting mode; (a) online simulation for MPC framework and benchmark $S o C$ trajectories for Profile 1 and (c) profile 2; (b) offline simulation for benchmark $S o C$ trajectories for Profile 1 and (d) Profile 2.

The effect of "trapped" battery charge can be understood in Figure 9, for Profile 1. At the region between 700 and $1000 \mathrm{~s}$ the barrier controller does not use the PTI, while the MPC framework, updated with the new information tries to use up the battery charge it did not use at the beginning of the mission. Not only that, but at $1500 \mathrm{~s}$, the MPC framework depletes the battery more aggressively than the optimal controller to catch up. After $2400 \mathrm{~s}$ the propulsive load is too small for the PTI to be used, and the barrier controller cannot use any remaining charge.

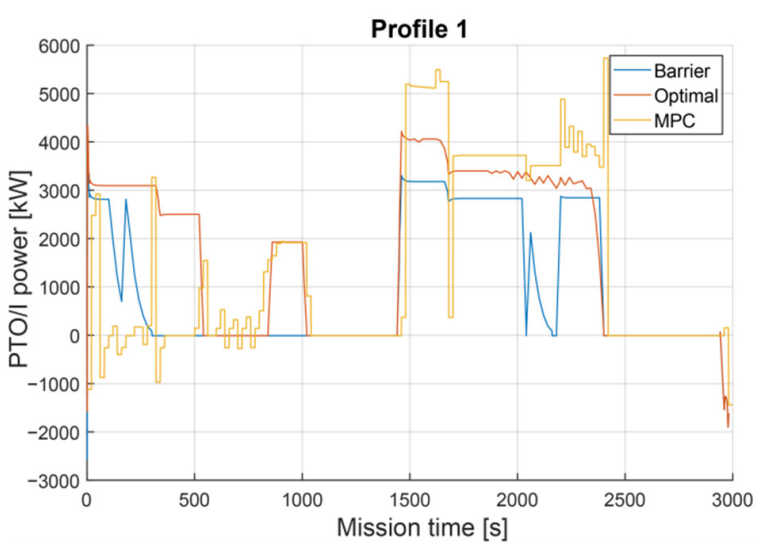

(a)

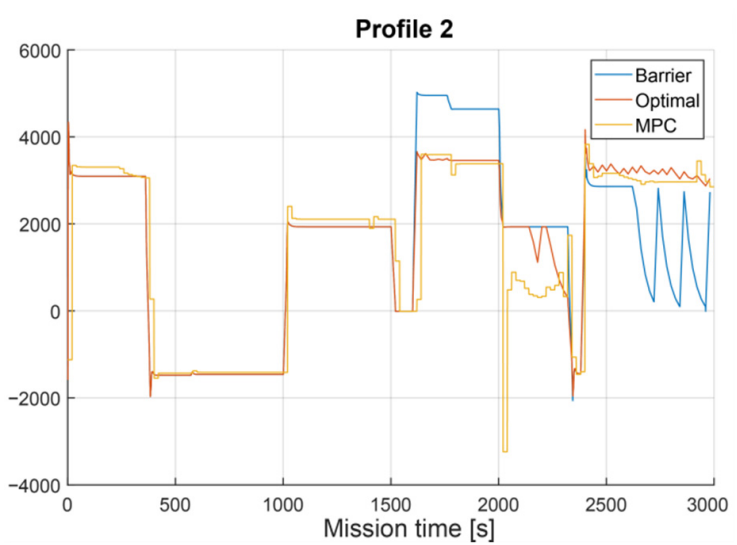

(b)

Figure 9. The PTO/I power trajectories on the online simulation for in charge-depleting mode for (a) Profile 1 and (b) Profile 2. 
Profile 2 presents little room for alternate control "paths", and a big portion of the optimal and barrier controllers coincide. The MPC framework follow very closely the setpoints of the optimal controller as it can be seen in Figure 9.

Two more profiles were tested for CD mode with similar results to Profile 2, with the MPC framework following consistently the optimal controller solution after the update point.

A parametric study for the position of the update point was carried out. Table 3 presents the results and demonstrates that if the "trapped" charge effect is present, there is a relatively wide update window for the MPC framework to yield savings and the savings are reducing consistently with later updates. In Figure 10 (right) it is shown that the PTO/I activity is consistent with the update points. For example, only the controller with an update point at $600 \mathrm{~s}$ follows the PTI setpoints of the optimal controller between 800 and $1000 \mathrm{~s}$, while it can be seen that for the controller with an update point at $1800 \mathrm{~s}$ the highest PTI setpoints are observed after that $1800 \mathrm{~s}$ mark in an attempt to deplete the "trapped" charge.

Table 3. Parametric study: update point (Profile 1).

\begin{tabular}{cccc}
\hline & \multicolumn{3}{c}{ Fuel Consumption [kg] } \\
\cline { 2 - 4 } & $\mathbf{6 0 0 ~ s}$ & $\mathbf{1 2 0 0 ~ s}$ & $\mathbf{1 8 0 0 ~ s}$ \\
\hline Optimal & 1787 & 1787 & 1787 \\
Barrier & 1878 & 1878 & 1878 \\
MPC & 1811 & 1813.4 & 1842 \\
& $(-3.56 \%)$ & $(-3.44 \%)$ & $(-1.92 \%)$ \\
\hline
\end{tabular}

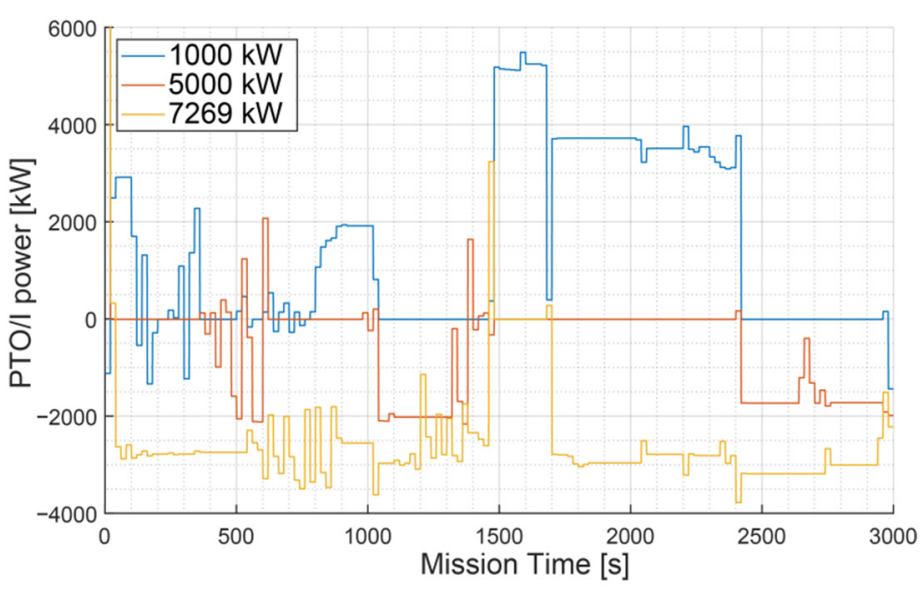

(a)

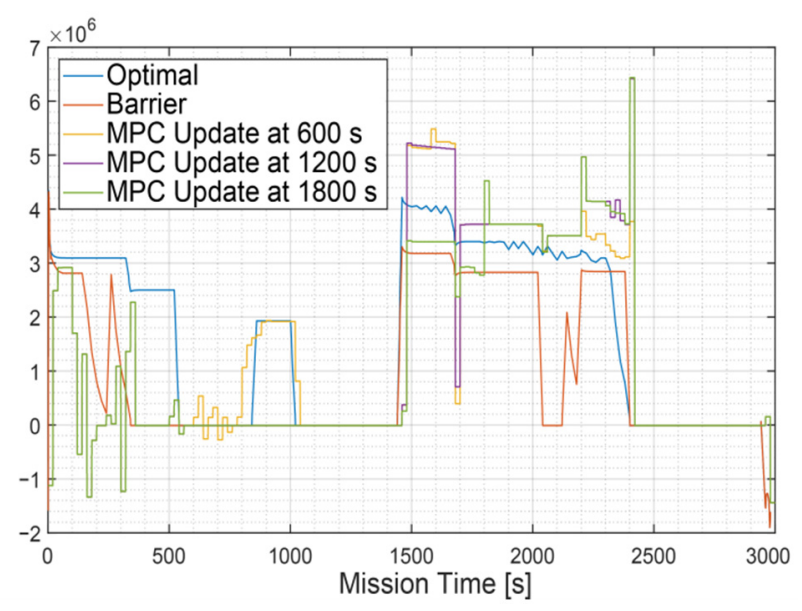

(b)

Figure 10. PTO/I activity for the (a) hotel load parametric study and (b) the update point study.

A second parametric study compared different values for the hotel loads. It was found that there are fuel savings when the electric machines are used, either in PTI or PTO mode (Figure 10a-design hotel load $7269 \mathrm{~kW}$ ). In the latter case the controller takes power off the shaft and offsets the main engine setpoints to the low consumption region (red cluster at $7 \mathrm{MW}$ on the main engine SFOC plot-Figure 11). For intermediate hotel loads (5 MW) the energy in the battery matches the hotel energy consumption of the mission and results in low PTO/PTI activity. The constraint on the torque of the electric machine is active and without the PTO/PTI mechanism to offset the setpoints of the main engine no reduction in fuel consumption was observed (Table 4). 


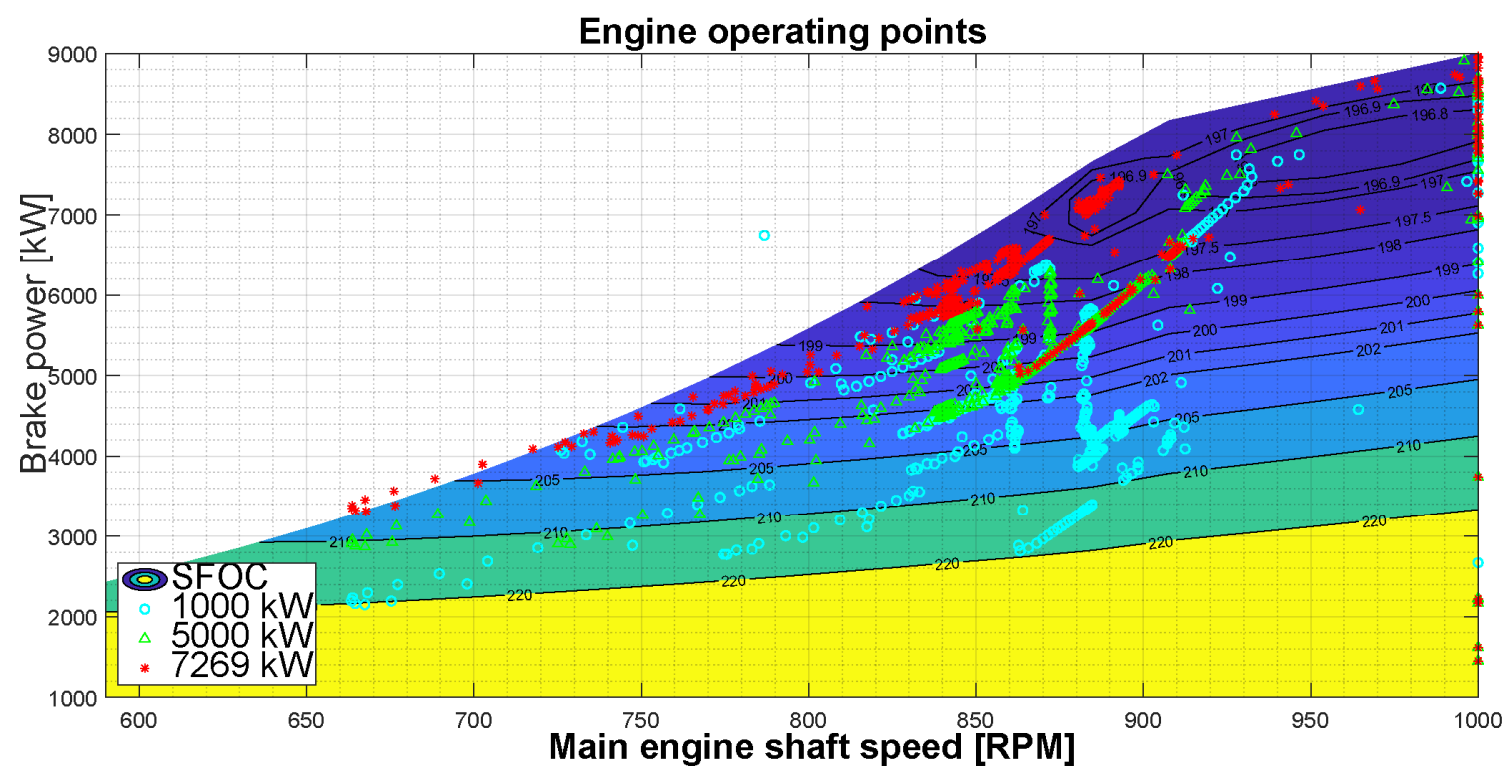

Figure 11. Parametric study: Main engine operating points from the MPC framework, corresponding to different simulations for the hotel demand, plotted on the SFOC contour plot.

Table 4. Parametric study: hotel power demand.

\begin{tabular}{cccc}
\hline & \multicolumn{3}{c}{ Fuel Consumption $[\mathbf{k g}]$} \\
\cline { 2 - 4 } & $\mathbf{1 ~ M W}$ & $\mathbf{5} \mathbf{M W}$ & $\mathbf{7 . 2 7} \mathbf{~ M W}$ \\
\hline Optimal & 1787 & 2442 & 2825 \\
Barrier & 1878 & 2447 & 2839 \\
MPC & 1811 & 2448 & 2826 \\
& $(-3.56 \%)$ & $(+0.04 \%)$ & $(-0.44 \%)$ \\
\hline
\end{tabular}

The profiles were also tested for CS mode. For the profiles in CS mode the utilisation of the battery was below $0.3 \%$ of the total installed charge and the induction machine was only initiated during low propulsive demand, where the operating limit of the main engines was activated. For Profile 1 the experiment was run again with the PTO/I torque limit relaxed from 0.3 to 0.1 and the hotel demand raised to $7269 \mathrm{~kW}$. The results are shown in Figure 12, where it can be seen that the MPC framework closely follows the optimal controllers. It is noted that no fuel savings were observed in any of the CS modes, results consistent with the findings in [6] were CS fuel savings due to battery utilisation were not found.

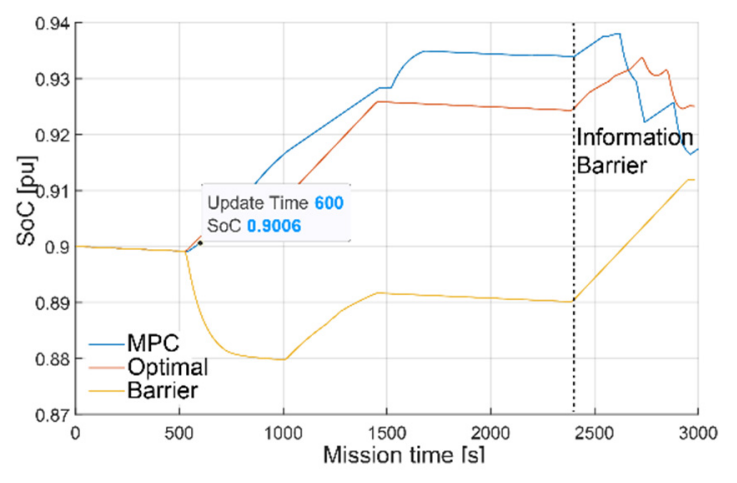

(a)

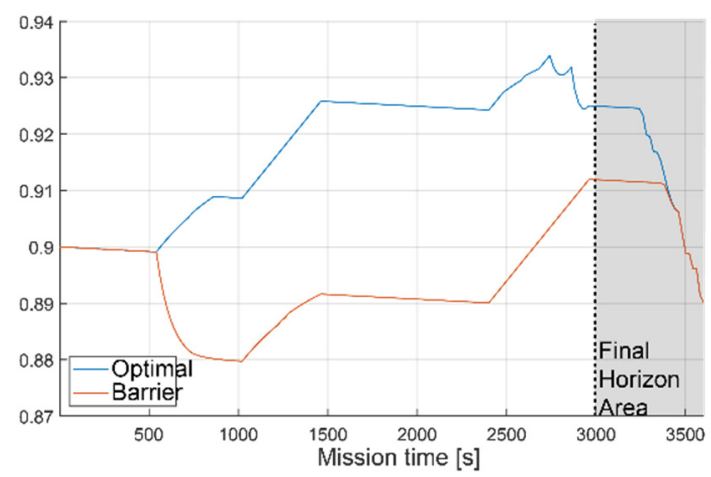

(b)

Figure 12. Cont. 


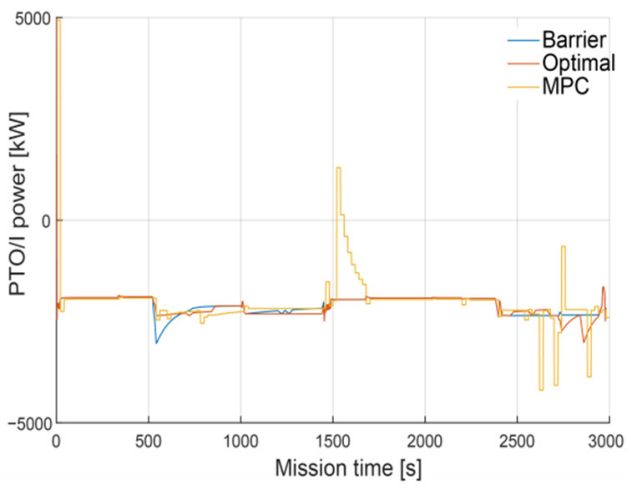

(c)

Figure 12. Charge-sustaining mode simulation results for Profile 1 ; (a) online simulation for MPC framework and benchmark SoC trajectories; (b) offline simulation for benchmark SoC trajectories; (c) the PTO/I power trajectories on the online simulation.

\section{Discussion}

The presence of a shipboard battery pack introduces loading sequence-specific, rather than profile-specific, system behavior. This should be addressed by control policies aiming for optimal fuel consumption and effective enforcement of the system constraints. The case study demonstrates the following about the proposed MPC framework:

- $\quad$ The MPC framework shows close-to-optimal performance and satisfies all operating constraints, including the integral constraints on the $S o C$, for all tested loading sequences and modes. A time interval of $600 \mathrm{~s}$ for both the prediction and the control horizon has been found to be sufficient for achieving such performance.

- In CD mode the consumption reduction due to utilisation of mission-scale predictions can be substantial. Compared to the fully-informed, optimal controller, the MPC framework selects higher power setpoints only after it receives the information for the updated profile, both in the standard and the parametric study (Figures 9a and 10b). This means that the primary factor for reducing the fuel consumed is the use of all the energy in the battery. This in turn offsets the consumption of the main engines and the generator to lower values. A reduction of up to $3.5 \%$ was achieved for this specific case study in CD mode and under specific loading sequences. In CS mode, savings due to unused charge avoidance are not possible.

- When the induction motors are active, the reduction in fuel consumption due to mission scale information is possible ( $0.4 \%$ reduction observed). The control inputs from the MPC framework yield fuel-efficient operating points in the envelope of the main engine. This is achieved by storing energy, via the induction motors, to the battery plant and using it at a later time, in such a way that the fuel consumed is minimised.

- For several loading sequences, the two benchmark solutions coincide partially or completely. In such cases, few solutions that satisfy all of the OCP's constraints exist, leading to a solution space where fuel consumption reduction due to use of mission scale information is insignificant. In the simulations for the MPC framework, the DP solvers in the RTG and MPC modules of the framework have been shown to be effective in finding these feasible solutions, adding to the controller's robustness.

- The computational load allows for an embedded controller. The controller framework implemented in Simulink ${ }^{\circledR}$, simulated together with the dynamic model, require less time to compute than the mission on a laptop computer.

The results of the study show the effectiveness of the proposed framework, compared to the state-of-the-art shipboard EMSs, particularly when handling mission-scale effects and integral constraints introduced by the battery system. Furthermore, the performance of the proposed framework in terms of fuel consumption and robustnessis close to the optimal solution. More specifically, it is demonstrated that the controller yields feasible control 
policies and is robust regarding the integral constraint on the battery $S o C$, addressing concerns identified in the literature, such as the insufficient peak demand availability observed in [25]. It is also capable of adapting to real-time updates on the future disturbance estimations, as opposed to the controller proposed in [38]. At the same time, it addresses the problem of instantaneous EMS (ECMS, A-ECMS), identified in [16], where the performance of the controller is poor under off-design power demand sequences, different from those used to tune the controller's equivalency factor(s).

These results may motivate future work to focus on incorporating online short-term and long-term prediction schemes into the MPC framework, in an attempt to design a complete controller solution (see Section 1.3). The lack of operating profile-specific parameters may enable early ship power plant design studies to quantify fuel consumption savings and battery sizing for different operating profiles and sequences. Finally, complex ship power plants can benefit from the framework's ability to readily incorporate additional control input variables and states as well as terms in the OCP's objective function.

Author Contributions: Conceptualisation, S.A., K.V. and M.K.; methodology, S.A.; software, S.A. and M.K.; validation, S.A. and M.K.; formal analysis, M.K.; investigation, S.A. and M.K.; resources, M.K.; data curation, S.A. and M.K.; writing-original draft preparation, S.A. and V.R.; writing-review and editing, S.A. and V.R.; visualisation, S.A. and M.K.; supervision, K.V. and M.K.; project administration, S.A.; funding acquisition, M.K. All authors have read and agreed to the published version of the manuscript.

Funding: This research received no external funding.

Institutional Review Board Statement: Not applicable.

Informed Consent Statement: Not applicable.

Data Availability Statement: Not applicable.

Acknowledgments: Special thanks goes to Damen Naval BV for supplying the Simulink ${ }^{\circledR}$ model of the naval vessel and providing necessary information and support throughout this study.

Conflicts of Interest: The authors declare no conflict of interest.

\section{Appendix A}

In order to find how to divide the total power demand among the available generator sets, the active number of generator sets can be found by an integer division $\mathrm{NoE}=\operatorname{div}\left(P_{\text {gen }}, P_{\text {genset, } n o m}\right)+1$, and then, by dividing the total power with this number the consumption can be found:

$$
P_{\text {genset }, i}=\frac{P_{\text {gen }}}{N o E}, i \in[1,2, \ldots, N o E] .
$$

The above yields optimal results in the common case where (a) the fuel consumption of the generator set is a convex function of its power demand and (b) the generators are identical.

By considering two generator sets with power setpoints $P_{g, 1}, P_{g, 2}$, what needs to be proven is that if point $C$ is the common operation point of the two engines, there exist no points $A$ and $B$, that cover the total power demand, such as:

$$
\begin{gathered}
\dot{m}_{f, a}+\dot{m}_{f, b}<2 \dot{m}_{f, c} \Leftrightarrow \\
f\left(P_{a, g, 1}\right)+f\left(P_{b, g, 2}\right)<2 f\left(P_{c, g, 12}\right), \\
P_{a, g, 1}<P_{c, g, 12}<P_{b, g, 2}
\end{gathered}
$$

This can be proven from the definition of convexity:

$$
\begin{gathered}
f(t x+(1-t) y) \leq t f(x)+(1-t) f(y), \\
t \in[0,1], x<y
\end{gathered}
$$


Now, since point $C$ is between $A$ and $B$, it can be expressed in the form:

$$
P_{c, g, 12}=t P_{a, g, 1}+(1-t) P_{b, g, 2}
$$

which yields:

$$
t=\frac{P_{c, g, 12}-P_{b, g, 2}}{P_{a, g, 1}-P_{b, g, 2}}
$$

and by substituting in the equation above the expression $2 P_{c, g, 12}=P_{a, g, 1}+P_{b, g, 2}=P_{g e n}$, which means that in both scenarios, the total power has to add up to the total power demand $P_{\text {gen }}$, yields that $t=1 / 2$. From the definition inequality (A3), and by substituting the $m_{f}$ function, it is now:

$$
\begin{gathered}
\dot{m}_{f, c} \leq \frac{1}{2} \dot{m}_{f, a}+\left(1-\frac{1}{2}\right) \dot{m}_{f, b} \Leftrightarrow \\
2 \dot{m}_{f, c} \leq \dot{m}_{f, a}+\dot{m}_{f, b}
\end{gathered}
$$

which can be generalised for more engines and which proves that the common power setpoint $P_{c, g, 12}=P_{g e n, i}$ from Equation (A1) is optimal. In the case of different engines, but their consumption functions are still convex, the formulation above can be extended, however, that case is not discussed here. Regarding the operating limits, the following inequalities should hold:

$$
\begin{gathered}
P_{\text {gen }, i} \in\left[P_{\text {gen, } \min }, P_{\text {gen,max }}\right] \\
P_{\text {gen }} \leq k_{g} P_{\text {gen }, \text { max }}
\end{gathered}
$$

where $k_{g}$ the number of generator sets available on the vessel.

\section{Appendix B}

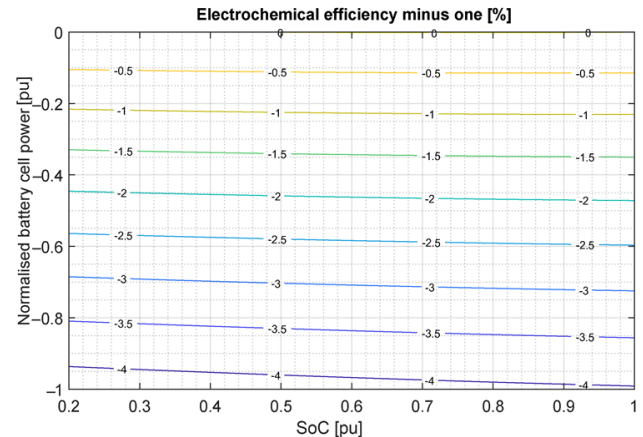

(a)

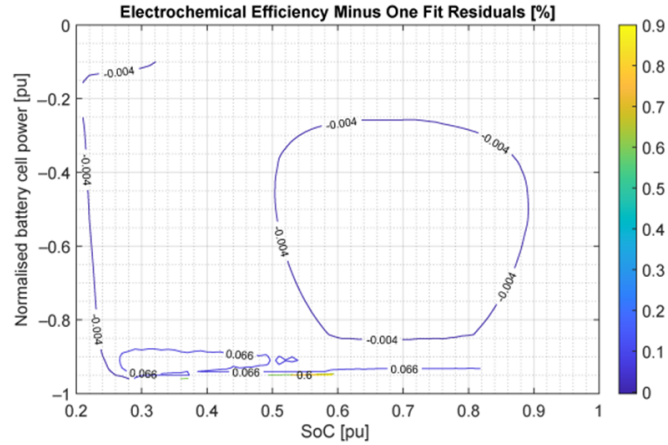

(b)

Figure A1. Fit for the electrochemical efficiency of the battery cell when charging minus one, as a function of normalised power and state of charge (a) and the residuals of the fit (b). R-square: 0.9996.

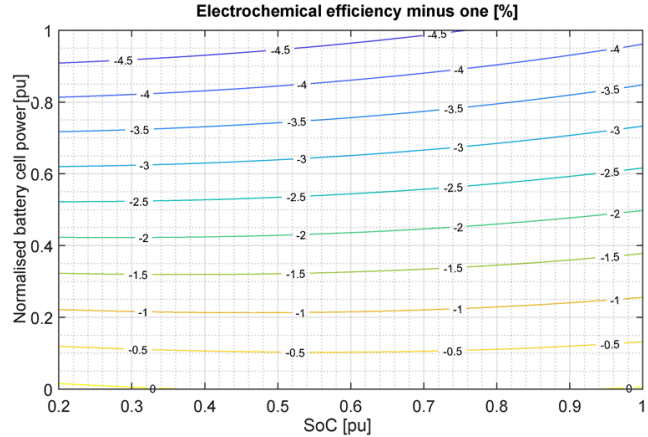

(a)

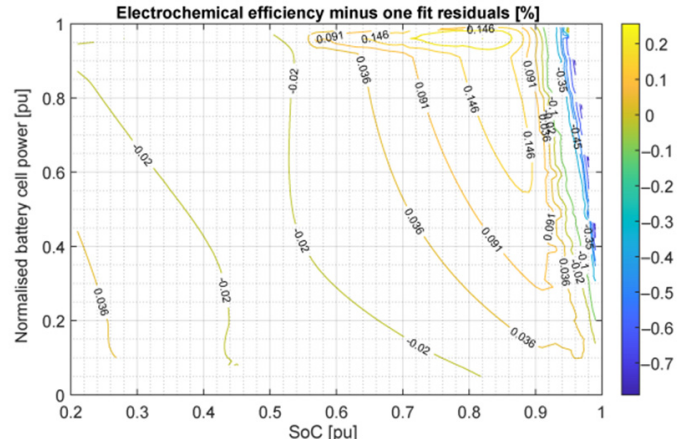

(b)

Figure A2. Fit for the electrochemical efficiency of the battery cell when discharging minus one, as a function of normalised power and state of charge (a) and the residuals of the fit (b). R-square: 0.9956. 


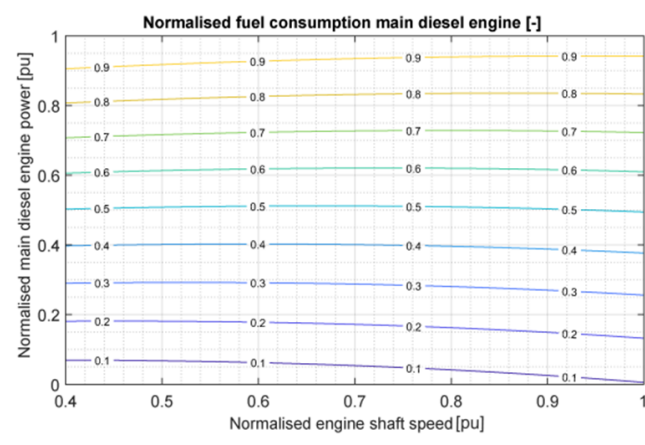

(a)

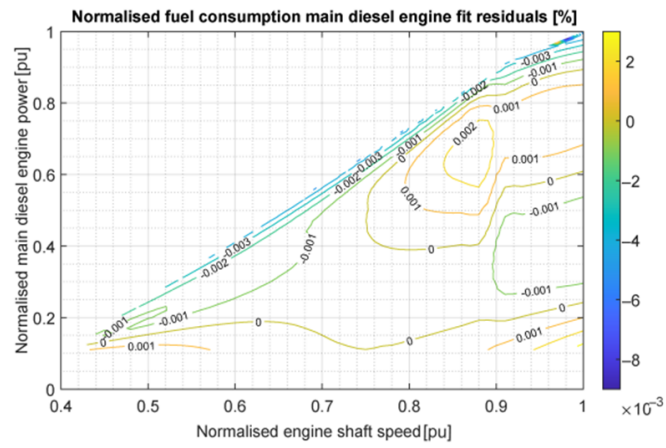

(b)

Figure A3. Polynomial fit for the normalised fuel consumption of the main engine, as a function of normalised engine power and shaft speed (a) and the residuals of the fit (b). R-square: 1.

Table A1. Case Study Parameter Values.

\begin{tabular}{|c|c|c|}
\hline Parameter & Value & Units \\
\hline$P_{\text {PTO/Iloss,nom }}$ & $1.9050 \times 10^{5}$ & $\mathrm{~W}$ \\
\hline$T_{\text {nom }}$ & $2.2037 \times 10^{5}$ & $\mathrm{Nm}$ \\
\hline$N_{\text {nom }}$ & 2.1667 & $\mathrm{~s}^{-1}$ \\
\hline$m_{f, D E, \text { nom }}$ & 0.4950 & $\mathrm{~kg} / \mathrm{s}$ \\
\hline$P_{D E, \text { nom }}$ & $9 \times 10^{7}$ & $\mathrm{~W}$ \\
\hline$N_{D E, \text { nom }}$ & 16.667 & $\mathrm{~s}^{-1}$ \\
\hline$m_{f, D G, n o m}$ & 0.1481 & $\mathrm{~kg} / \mathrm{s}$ \\
\hline$P_{f, g e n, \text { nom }}$ & $2.6923 \times 10^{6}$ & W \\
\hline$k_{p}$ & 2 & \\
\hline$n_{\text {ser }}$ & 34 & \\
\hline$n_{\text {par }}$ & 102 & \\
\hline$P_{\text {cell,max }}$ & $1.8417 \times 10^{3}$ & W \\
\hline$Q_{\text {cell }, 0}$ & 48.06 & As \\
\hline$I_{\text {nom, los }}$ & 206.670 & A \\
\hline$I_{b a t, A C, \text { nom }}$ & 10287 & A \\
\hline$p f$ & 0.8 & \\
\hline$V_{\text {line }}$ & 440 & V \\
\hline$i_{G B, B}$ & 7.692 & \\
\hline$i_{G B, \text { drive }}$ & 1 & \\
\hline$M_{n, \min }$ & 0.3 & \\
\hline$P_{D E, n, \min }$ & 0.45 & \\
\hline SoC $\min$ & 0.2 & \\
\hline$P_{D G, n, \min }$ & 0.4 & \\
\hline
\end{tabular}

Table A2. List ofAbbreviations.

\begin{tabular}{cc}
\hline Parameter & Value \\
\hline CD & Charge Depleting \\
CS & Charge Sustaining \\
DAE & Differential and Algebraic Equations \\
DoF & Degrees of Freedom \\
DP & Dynamic Programming \\
ECMS & Equivalent Consumption Minimisation Strategy \\
EMS & Energy Management Strategy \\
ESC & End-State Constraint \\
ESS & Energy Storage System \\
\hline
\end{tabular}


Table A2. Cont.

\begin{tabular}{cc}
\hline Parameter & Value \\
\hline IBP & Information Barrier Point \\
IC & Internal Combustion \\
MPC & Model Prodictive Control \\
OCP & Optimal Control Problem \\
PTO/I & Power take-off/in \\
RTG & Reference Trajectory Generation \\
SFOC & Specific Fuel Oil Consumption \\
SoC & State of Charge \\
\hline
\end{tabular}

\section{References}

1. International Maritime Organization-Fourth IMO GHG Study 2020 Executive-Summary. Available online: https:/ wwwcdn. imo.org/localresources/en/OurWork/Environment/Documents/Fourth\%20IMO\%20GHG\%20Study\%202020\%20ExecutiveSummary.pdf (accessed on 21 July 2021).

2. Sui, C.; de Vos, P.; Stapersma, D.; Visser, K.; Ding, Y. Fuel consumption and emissions of ocean-going cargo ship with hybrid propulsion and different fuels over voyage. J. Mar. Sci. Eng. 2020, 8, 588. [CrossRef]

3. Hwang, S.; Jeong, B.; Jung, K.; Kim, M.; Zhou, P. Life cycle assessment of LNG fueled vessel in domestic services. J. Mar. Sci. Eng. 2019, 7, 359. [CrossRef]

4. Kim, K.; Roh, G.; Kim, W.; Chun, K. A preliminary study on an alternative ship propulsion system fueled by ammonia: Environmental and economic assessments. J. Mar. Sci. Eng. 2020, 8, 183. [CrossRef]

5. Lamas Galdo, M.I.; Castro-Santos, L.; Rodriguez Vidal, C.G. Numerical analysis of NOx reduction using ammonia injection and comparison with water injection. J. Mar. Sci. Eng. 2020, 8, 109. [CrossRef]

6. Witkowski, K. Research of the effectiveness of selected methods of reducing toxic exhaust emissions of marine diesel engines. J. Mar. Sci. Eng. 2020, 8, 452. [CrossRef]

7. Puškár, M.; Kopas, M.; Sabadka, D.; Kliment, M.; Šoltésová, M. Reduction of the gaseous emissions in the marine diesel engine using biodiesel mixtures. J. Mar. Sci. Eng. 2020, 8, 330. [CrossRef]

8. Lashway, C.R.; Elsayed, A.T.; Mohammed, O.A. Hybrid energy storage management in ship power systems with multiple pulsed loads. Electr. Power Syst. Res. 2016, 141, 50-62. [CrossRef]

9. Geertsma, R.D.; Negenborn, R.R.; Visser, K.; Hopman, J.J. Design and control of hybrid power and propulsion systems for smart ships: A review of developments. Appl. Energy 2017, 194, 30-54. [CrossRef]

10. Georgescu, I.; Godjevac, M.; Visser, K. Efficiency constraints of energy storage for on-board power systems. Ocean. Eng. 2018, 162, 239-247. [CrossRef]

11. Bloomberg-Batteries for Electric Cars Speed toward a Tipping Point. Available online: https://www.bloomberg.com/news/ articles / 2020-12-16/electric-cars-are-about-to-be-as-cheap-as-gas-powered-models (accessed on 31 January 2021).

12. Berckmans, G.; Messagie, M.; Smekens, J.; Omar, N.; Vanhaverbeke, L.; Van Mierlo, J. Cost projection of state of the art lithium-ion batteries for electric vehicles up to 2030. Energies 2017, 10, 1314. [CrossRef]

13. Zahedi, B.; Norum, L.E.; Ludvigsen, K.B. Optimized efficiency of all-electric ships by dc hybrid power systems. J. Power Sources 2014, 255, 341-354. [CrossRef]

14. Godjevac, M.; Mestemaker, B.T.; Visser, K.; Lyu, Z.; Boonen, E.J.; van der Veen, F.; Malikouti, C. Electrical energy storage for dynamic positiong operations: Investigation of three application case. In Proceedings of the 2017 IEEE Electric Ship Technologies Symposium (ESTS), Arlington, VA, USA, 14-17 August 2017; pp. 182-186.

15. Dedes, E.K.; Hudson, D.A.; Turnock, S.R. Investigation of Diesel Hybrid systems for fuel oil reduction in slow speed ocean going ships. Energy 2016, 114, 444-456. [CrossRef]

16. Kalikatzarakis, M.; Geertsma, R.D.; Boonen, E.J.; Visser, K.; Negenborn, R.R. Ship energy management for hybrid propulsion and power supply with shore charging. Control Eng. Pract. 2018, 76, 133-154. [CrossRef]

17. Mauro, F.; Ghigliossi, E.; Bucci, V.; Marinó, A. Design of hybrid-electric megayachts: The impact of operative profile and smart berthing infrastructures. J. Mar. Sci. Eng. 2021, 9, 186. [CrossRef]

18. Papanikolaou, A.D. Review of the Design and Technology Challenges of Zero-Emission, Battery-Driven Fast Marine Vehicles. J. Mar. Sci. Eng. 2020, 8, 941. [CrossRef]

19. Papanikolaou, A.; Xing-Kaeding, Y.; Strobel, J.; Kanellopoulou, A.; Zaraphonitis, G.; Tolo, E. Numerical and Experimental Optimization Study on a Fast, Zero Emission Catamaran. J. Mar. Sci. Eng. 2020, 8, 657. [CrossRef]

20. Bassam, A.M.; Phillips, A.B.; Turnock, S.R.; Wilson, P.A. Development of a multi-scheme energy management strategy for a hybrid fuel cell driven passenger ship. Int. J. Hydrog. Energy 2017, 42, 623-635. [CrossRef]

21. Zhu, L.; Han, J.; Peng, D.; Wang, T.; Tang, T.; Charpentier, J.-F. Fuzzy logic based energy management strategy for a fuel cell/battery/ultra-capacitor hybrid ship. In Proceedings of the 2014 First International Conference on Green Energy ICGE 2014, Sfax, Tunisia, 25-27 March 2014; pp. 107-112. 
22. Jeong, B.; Jeon, H.; Kim, S.; Kim, J.; Zhou, P. Evaluation of the lifecycle environmental benefits of full battery powered ships: Comparative analysis of marine diesel and electricity. J. Mar. Sci. Eng. 2020, 8, 580. [CrossRef]

23. Sciarretta, A.; Guzzella, L. Control of hybrid electric vehicles. IEEE Control Syst. Mag. 2007, 27, 60-70.

24. Yuan, Y.; Zhang, T.; Shen, B.; Yan, X.; Long, T. A fuzzy logic energy management strategy for a photovoltaic/diesel/battery hybrid ship based on experimental database. Energies 2018, 11, 2211. [CrossRef]

25. Yuan, L.C.; Tjahjowidodo, T.; Lee, G.S.; Chan, R.; Ådnanes, A.K. Equivalent consumption minimization strategy for hybrid all-electric tugboats to optimize fuel savings. In Proceedings of the 2016 American Control Conference (ACC), Boston, MA, USA, 6-8 July 2016; pp. 6803-6808.

26. Vu, T.L.; Ayu, A.A.; Dhupia, J.S.; Kennedy, L.; Ådnanes, A.K. Power management for electric tugboats through operating load estimation. IEEE Trans. Control Syst. Technol. 2015, 23, 2375-2382. [CrossRef]

27. Xiang, W.; Yin, J.; Lim, G. An ant colony optimization approach for solving an operating room surgery scheduling problem. Comput. Ind. Eng. 2015, 85, 335-345. [CrossRef]

28. Sciberras, E.A.; Zahawi, B.; Atkinson, D.J.; Breijs, A.; van Vugt, J.H. Managing shipboard energy: A stochastic approach special issue on marine systems electrification. IEEE Trans. Transp. Electrif. 2016, 2, 538-546. [CrossRef]

29. Yan, F.; Wang, J.; Huang, K. Hybrid electric vehicle model predictive control torque-split strategy incorporating engine transient characteristics. IEEE Trans. Veh. Technol. 2012, 61, 2458-2467. [CrossRef]

30. Bordons, C.; Garcia-Torres, F.; Ridao, M.A. Microgrid as a New Paradigm for the Electrical System. In Model Predictive Control of Microgrids; Grimble, M.J., Ferrara, A., Eds.; Advances in Industrial Control; Springer Nature: Cham, Switzerland, 2020; pp. 1-11.

31. Serrao, L.; Onori, S.; Rizzoni, G. A comparative analysis of energy management strategies for hybrid electric vehicles. J. Dyn. Syst. Meas. Control 2011, 133, 031012. [CrossRef]

32. Fu, L.; Ümit, Ö.; Tulpule, P.; Marano, V. Real-time energy management and sensitivity study for hybrid electric vehicles. In Proceedings of the 2011 American Control Conference, San Francisco, CA, USA, 29 June-1 July 2011; pp. $2113-2118$.

33. Finkeldei, E.; Back, M. Implementing an mpc algorithm in a vehicle with a hybrid powertrain using telematics as a sensor for powertrain control. IFAC Proc. Vol. 2004, 37, 433-438. [CrossRef]

34. Sun, C.; Moura, S.J.; Hu, X.; Hedrick, J.K.; Sun, F. Dynamic traffic feedback data enabled energy management in plug-in hybrid electric vehicles. IEEE Trans. Control Syst. Technol. 2014, 23, 1075-1086.

35. Hou, J.; Sun, J.; Hofmann, H. Mitigating power fluctuations in electrical ship propulsion using model predictive control with hybrid energy storage system. In Proceedings of the 2014 American Control Conference, Portland, OR, USA, 4-6 June 2014; pp. 4366-4371.

36. Haseltalab, A.; Negenborn, R.R.; Lodewijks, G. Multi-level predictive control for energy management of hybrid ships in the presence of uncertainty and environmental disturbances. IFAC-PapersOnLine 2016, 49, 90-95. [CrossRef]

37. Papalambrou, G.; Samokhin, S.; Topaloglou, S.; Planakis, N.; Kyrtatos, N.; Zenger, K. Model predictive control for hybrid diesel-electric marine propulsion. IFAC-PapersOnLine 2017, 50, 11064-11069. [CrossRef]

38. Huotari, J.; Ritari, A.; Vepsäläinen, J.; Tammi, K. Hybrid ship unit commitment with demand prediction and model predictive control. Energies 2020, 13, 4748. [CrossRef]

39. Geertsma, R. Autonomous Control for Adaptive Ships with Hybrid Propulsion and Power Generation. Ph.D. Thesis, Technical University of Delft, Delft, The Netherlands, 2019.

40. Wu, M.; Stefanakos, C.; Gao, Z. Multi-Step-Ahead Forecasting of Wave Conditions Based on a Physics-Based Machine Learning (PBML) Model for Marine Operations. J. Mar. Sci. Eng. 2020, 8, 992. [CrossRef]

41. Pennino, S.; Gaglione, S.; Innac, A.; Piscopo, V.; Scamardella, A. Development of a new ship adaptive weather routing model based on seakeeping analysis and optimization. J. Mar. Sci. Eng. 2020, 8, 270. [CrossRef]

42. Onori, S.; Serrao, L.; Rizzoni, G. Adaptive Optimal Supervisory Control Methods. In Hybrid Electric Vehicles: Energy Management Strategies; Basar, T., Bicchi, A., Krstic, M., Eds.; Springer: London, UK, 2016; pp. 79-88.

43. Guzzella, L.; Sciarretta, A. Electric and Hybrid-Electric Propulsion Systems. In Vehicle Propulsion Systems, 3rd ed.; Springer: Berlin/Heidelberg, Germany, 2007; pp. 10-130.

44. Sundstrom, O.; Guzzella, L. A generic dynamic programming Matlab function. In Proceedings of the 2009 IEEE control applications (CCA) \& intelligent control (ISIC), St. Petersburg, Russia, 8-10 July 2009; pp. 1625-1630.

45. Murgovski, N.; Johannesson, L.; Sjöberg, J.; Egardt, B. Component sizing of a plug-in hybrid electric powertrain via convex optimization. Mechatronics 2012, 22, 106-120. [CrossRef]

46. Faulwasser, T.; Grüne, L.; Müller, M.A. Economic nonlinear model predictive control. Now Found. Trends 2018, 5, 1-98.

47. Hovgaard, T.G.; Edlund, K.; Jørgensen, J.B. The potential of economic MPC for power management. In Proceedings of the 49th IEEE Conference on Decision and Control (CDC), Atlanta, GA, USA, 15-17 December 2010; pp. 7533-7538.

48. Ferramosca, A.; Rawlings, J.B.; Limón, D.; Camacho, E.F. Economic MPC for a changing economic criterion. In Proceedings of the 49th IEEE Conference on Decision and Control (CDC), Atlanta, GA, USA, 15-17 December 2010; pp. 6131-6136.

49. Rawlings, J.B.; Bonné, D.; Jorgensen, J.B.; Venkat, A.N.; Jorgensen, S.B. Unreachable setpoints in model predictive control. IEEE Trans. Autom. Control 2008, 53, 2209-2215. [CrossRef] 
50. Vu, T.L.; Dhupia, J.S.; Ayu, A.A.; Kennedy, L.; Adnanes, A.K. Optimal power management for electric tugboats with unknown load demand. In Proceedings of the 2014 American Control Conference, Portland, OR, USA, 4-6 June 2014 ; pp. 1578-1583.

51. Nijhuis, M.; Gibescu, M.; Cobben, J.F. Bottom-up Markov Chain Monte Carlo approach for scenario based residential load modelling with publicly available data. Energy Build. 2016, 112, 121-129. [CrossRef] 